\title{
Maternal Low-Fat Diet Programs the Hepatic Epigenome despite Exposure to an Obesogenic Postnatal Diet
}

\author{
Laura Moody ${ }^{1}$, Justin Shao ${ }^{2}$, Hong Chen ${ }^{3}\left[\mathbb{D}\right.$ and Yuan-Xiang Pan ${ }^{4, *(\mathbb{D})}$ \\ 1 Division of Nutritional Sciences, University of Illinois at Urbana-Champaign, Urbana, IL 61801, USA \\ 2 Department of Food Science and Human Nutrition, University of Illinois at Urbana-Champaign, \\ Exeter High School, 1 Blue Hawk Drive, Exeter, NH 03833, USA \\ 3 Department of Food Science and Human Nutrition, Division of Nutritional Sciences, \\ University of Illinois at Urbana-Champaign, Urbana, IL 61801, USA \\ 4 Department of Food Science and Human Nutrition, Division of Nutritional Sciences, \\ and Illinois Informatics Institute, University of Illinois at Urbana-Champaign, Urbana, IL 61801, USA \\ * Correspondence: yxpan@illinois.edu; Tel.: +1-217-333-3466
}

Received: 29 June 2019; Accepted: 27 August 2019; Published: 3 September 2019

\begin{abstract}
Obesity and metabolic disease present a danger to long-term health outcomes. It has been hypothesized that epigenetic marks established during early life might program individuals and have either beneficial or harmful consequences later in life. In the present study, we examined whether maternal diet alters DNA methylation and whether such modifications persist after an obesogenic postnatal dietary challenge. During gestation and lactation, male Sprague-Dawley rats were exposed to either a high-fat diet (HF; $n=10)$ or low-fat diet (LF; $n=10)$. After weaning, all animals were fed a HF diet for an additional nine weeks. There were no differences observed in food intake or body weight between groups. Hepatic DNA methylation was quantified using both methylated DNA immunoprecipitation sequencing (MeDIP-seq) and methylation-sensitive restriction enzyme sequencing (MRE-seq). Overall, 1419 differentially methylated regions (DMRs) were identified. DMRs tended to be located in $\mathrm{CPG}$ shores and were enriched for genes involved in metabolism and cancer. Gene expression was measured for 31 genes in these pathways. Map3k5 and Igf1 $r$ were confirmed to be differentially expressed. Finally, we attempted to quantify the functional relevance of intergenic DMRs. Using chromatin contact data, we saw that conserved DMRs were topologically associated with metabolism genes, which were associated with differential expression of Adh5, Enox1, and Pik3c3. We show that although maternal dietary fat is unable to reverse offspring weight gain in response to a postnatal obesogenic diet, early life diet does program the hepatic methylome. Epigenetic alterations occur primarily in metabolic and cancer pathways and are associated with altered gene expression, but it is unclear whether they bear consequence later in life.
\end{abstract}

Keywords: DO Had; developmental programming; early life nutrition; gene-environment interactions; hepatic methylome

\section{Introduction}

Obesogenic diets are associated with a host of chronic diseases. Calorie-dense diets, including those that are high in fat and sucrose, have been shown to blunt insulin sensitivity [1,2], increase the risk for cardiovascular disease [3,4], and increase the incidence of certain types of cancer $[5,6]$. While consumption of a high-fat (HF) diet is known to produce undesirable outcomes, it has been suggested that maternal diet may play an important role in preventing the negative consequences of poor postnatal diet. For instance, compared to control-fed mice, mice fed an obesogenic diet after 
weaning had larger adipocytes, higher fasting glucose and insulin levels, and reduced expression of insulin signaling proteins $[7,8]$. However, a maternal low-fat (LF) diet significantly reduced adipocyte size, lowered fasting glucose and insulin, and ameliorated the protein expression changes. Similarly, an obesogenic postnatal diet only resulted in cardiac hypertrophy and elevated fibrosis if it was preceded by an obesogenic prenatal diet, but not if it was preceded by a prenatal LF diet [9].

It has been hypothesized that perinatal nutrition acts via epigenetic mechanisms to mediate long-term health outcomes. Early life is marked by a highly dynamic epigenetic state. In particular, DNA methylation that is established during gestation is thought to persist into adulthood. Previously, maternal intake of micronutrients such as folate and choline, as well as protein restriction has been associated with altered DNA methylation in adult offspring [10-12]. Macronutrient consumption, particularly a HF diet, has been shown to produce methylation differences in energy homeostasis genes, peroxisome proliferator-activated receptor $\alpha$ (Ppara) [13], inflammatory genes, toll-like receptors 1 and 2 (Tlr1 and Tlr2) [14], and the hepatic cell cycle inhibitor, cyclin-dependent kinase inhibitor (Cdkn1a) [15].

In this experiment, we examined the role of maternal diet on epigenetic programming. Pregnant Sprague-Dawley rats were fed either a HF or a LF diet during gestation and lactation. After weaning, male pups from both groups were fed a HF diet until 12 weeks of age. DNA methylation was measured in hepatic tissue using complementary methylated DNA immunoprecipitation sequencing (MeDIP-seq) and methylation-sensitive restriction enzyme sequencing (MRE-seq). Differentially methylated regions (DMRs) were characterized based on association with CpG islands and genes. Pathway analysis was performed, and gene expression was measured. Finally, we attempted to functionally interpret intergenic DMRs by examining the chromatin structure around each conserved locus.

\section{Materials and Methods}

\subsection{Animals and Diets}

Timed-pregnant Sprague-Dawley rat dams (Charles River Laboratories, Wilmington, MA) were randomized into two groups for dietary treatment during gestation and lactation. The first group of 12 rats received a high-fat diet (HF; Research Diets, Inc.; $45 \%$ calories from fat), and the second group of 12 rats received a low-fat diet (LF; AIN93G Research Diets, Inc.; 16\% calories from fat). Dams were individually housed with their pups in standard polycarbonate cages in a humidity- and temperature-controlled room on a 12-h light-dark cycle with ad libitum access to food and drinking water [16]. On postnatal day 21, male offspring ( $n=10$ rats per group from 10 different dams) were all given ad libitum access to only a HF diet until postnatal week 12 . Animals were then sacrificed, and the median lobe of the liver was frozen in liquid nitrogen and stored at $-70^{\circ} \mathrm{C}$. It has been shown that lobes differ in their capacity to store minerals [17], susceptibility to certain diseases [18], and transcriptomic profiles [19]. In rodents, the left lobe is developmentally distinct from the right, median, and caudate lobes. By selecting the median lobe, not only do we reduce variation between tissue samples, but we also choose a representative region that is developmentally similar to the majority of the liver. Institutional and governmental regulations regarding the ethical use of animals were followed during the study. The protocol for the ethical use of animals was approved by the Institutional Animal Care and Use Committee (IACUC protocol no. 09112).

\subsection{Methylated DNA Immunoprecipitation (MeDIP) and Methylation-Sensitive Restriction Enzyme (MRE) Sequencing}

Genomic DNA was isolated using previously published methods [20]. Animals were chosen through an extensive screening process in which gene expression and histology were measured, and the best representatives from each group were used for sequencing. Complementary MeDIP-seq and MRE-seq were then performed using previously published protocols [20]. Briefly, MeDIP utilizes antibodies against 5-methylcytidine to quantify methylated DNA sequences, while MRE-seq uses 
restriction enzymes that cut at unmethylated CpG sites. MeDIP-seq provides better coverage and MRE-seq offers superior resolution, so that when combined the methylome can be quantified with high accuracy [21,22]. Antibodies, restriction enzymes, DNA fragmentation, and library preparation procedures have been detailed by Li et al. [23].

\subsection{DMR Identification}

MeDIP-seq and MRE-seq data analysis were performed using the methylMnM package in R. A detailed procedure is presented by Zhang et al. [24]. In brief, the rat genome (Rn4) was partitioned into 500 bp bins, and MeDIP-seq and MRE-seq data were modeled as a function of CpG content, MRE site content, and methylation level within each bin. We used the methylMnM algorithm to test the null hypothesis that methylation level was the same between the two samples. The normalized MeDIP and MRE reads were treated as mutually independent Poisson random variables and their expected values were calculated for each sample within each bin. A test statistic and $p$-value were calculated assuming that the joint distribution of the random variables followed a multinomial distribution. Bins with a Benjamini-Hochberg false discovery rate (FDR) $p$-value $<0.05$ were considered significant and were called differentially methylated regions (DMRs). Further information regarding methylMnM can be found on the Bioconductor website: http://www.bioconductor.org/packages/release/bioc/html/ methylMnM.html) [23,24].

\subsection{Annotation and Pathway Analysis}

Next, we examined the association between DMRs and CpG islands. CpG islands were defined based on three criteria: (i) sequence length greater than $200 \mathrm{bp}$, (ii) GC content greater than 50\%, and (iii) an observed-to-expected CpG ratio greater than 0.6 . Shores were the 2,000 bp regions upstream and downstream of each island [25]. We also annotated DMRs based on location relative to genes. DMRs were classified as either intergenic, intragenic, downstream, or in the promoter. Promoter regions were defined as the $1500 \mathrm{bp}$ upstream of the transcription start site (TSS), while downstream regions were defined as the $1500 \mathrm{bp}$ downstream of the transcription end site (TES) [16]. Intragenic regions included both exonic and intronic sequences of the gene body. Intergenic DMRs fell outside any gene body or $1500 \mathrm{bp}$ flanking region.

Differentially methylated genes (DMGs) were annotated with Gene Ontology (GO) and Kyoto Encyclopedia of Genes and Genomes (KEGG) Pathway terms. DAVID Bioinformatics Resources version 6.7 was used to identify enriched annotation clusters and pathways with a high degree of differential methylation (http://david.abcc.ncifcrf.gov/) [26]. Functional clusters were required to have at least 2 GO and/or KEGG Pathway terms, and the majority of terms within each cluster were required to have a Benjamini-Hochberg FDR $p$-value $<0.05$. Similarly, we report KEGG pathways that contained at least 2 DMGs and had a fold enrichment $\geq 1.5$ (based on the proportion of a specific pathway's genes that were DMGs).

\subsection{Methylation Specific PCR}

To validate sequencing results, methylation specific PCR (MSP) was used to quantify DNA methylation in all animals. Primer design, genomic DNA isolation, bisulfite conversion, and qPCR were performed using published methods [20]. The relative amount of methylated DNA was calculated as a ratio using the following equation: \% methylated DNA = (quantity of methylated DNA)/(quantity of methylated DNA + quantity of unmethylated DNA) $\times 100 \%$. All MSP primer information can be found in Table 1. 
Table 1. Methylation specific PCR (MSP) primers.

\begin{tabular}{|c|c|c|c|c|c|}
\hline Gene & CpG Site & Position & Methylation & Primers $\left(5^{\prime} \rightarrow 3^{\prime}\right)$ & Efficiency * \\
\hline \multirow{16}{*}{ Gpam } & \multirow{4}{*}{ CpG 1} & Forward $+52,479$ & $\mathrm{U}$ & GTAGTGGAATAAGAAGTTTTCGGAG & \multirow{2}{*}{$98.20 \%$} \\
\hline & & Reverse $+52,587$ & $\mathrm{U}$ & ACCTTCAAATAACAATCACGCTAC & \\
\hline & & Forward $+52,485$ & $\mathrm{M}$ & AGAGTAGTAGTGGAATAAGAAGTTTTTGG & \multirow{2}{*}{$99.10 \%$} \\
\hline & & Reverse $+52,586$ & M & CACCTTCAAATAACAATCACACTAC & \\
\hline & \multirow{4}{*}{ CpG 2} & Forward $+44,337$ & $\mathrm{U}$ & GGTGGAGAGGTATTTGTTATGGA & \multirow{2}{*}{$108.20 \%$} \\
\hline & & Reverse $+44,416$ & $\mathrm{U}$ & CСАСАСААТСТАСАААСТTСАСАA & \\
\hline & & Forward $+44,332$ & $\mathrm{M}$ & TTAGAGGTGGAGAGGTATTTGTTAC & $101.19 \%$ \\
\hline & & Reverse $+44,414$ & M & ACACAATCTACAAACTTCACGAAAA & \\
\hline & \multirow{4}{*}{ CpG 3} & Forward +7619 & $\mathrm{U}$ & TGTAATTTTTTATTTTAATTTATGTGATTTTTGA & \multirow{2}{*}{$95.56 \%$} \\
\hline & & Reverse +7736 & $\mathrm{U}$ & TTTCTACTTCACAATTACTAATCAACCCA & \\
\hline & & Forward +7633 & M & TTAATTTACGTGATTTTTGATTGTTATTATTTT & \multirow{2}{*}{$98.50 \%$} \\
\hline & & Reverse +7736 & $\mathrm{M}$ & CTACTTCACGATTACTAATCAACCCG & \\
\hline & \multirow{4}{*}{ CpG 4} & Forward +7288 & $\mathrm{U}$ & AAGTTAAGTTGTAGTGGTTGGGTAATTG & \multirow{2}{*}{$93.47 \%$} \\
\hline & & Reverse +7360 & $\mathrm{U}$ & CCCACTTATTTTAAACAACATCAAACC & \\
\hline & & Forward +7289 & M & AGTCGTAGTGGTCGGGTAATCG & \multirow{2}{*}{$107.81 \%$} \\
\hline & & Reverse +7357 & $\mathrm{M}$ & CCGCTTATTTTAAACAACATCGAA & \\
\hline \multirow{24}{*}{ Myh7b } & \multirow{4}{*}{ CpG 1} & Forward +9089 & $\mathrm{U}$ & TGGGTTCGTGTGGGAAATG & \multirow{2}{*}{$99.33 \%$} \\
\hline & & Reverse +9181 & $\mathrm{U}$ & ССАССТСААСТСТСССТАААСАА & \\
\hline & & Forward +9089 & $\mathrm{M}$ & CGGGTTCGTGTGGGAAAC & \multirow{2}{*}{$92.99 \%$} \\
\hline & & Reverse +9181 & $\mathrm{M}$ & CСGССТСААСТСТСССТАAА & \\
\hline & \multirow{4}{*}{ CpG 2} & Forward +9607 & $\mathrm{U}$ & AGGAGTATAAATGGGAGGGTATTGATT & \multirow{2}{*}{$91.86 \%$} \\
\hline & & Reverse +9757 & $\mathrm{U}$ & САТАСАСААСТТССААСАССАТСС & \\
\hline & & Forward +9621 & $\mathrm{M}$ & CGTGTTGGAGTAGGAGGAGTATAAAC & \multirow{2}{*}{$102.11 \%$} \\
\hline & & Reverse +9753 & $\mathrm{M}$ & CGCAACTTCCGACACCATC & \\
\hline & \multirow{4}{*}{ CpG 3} & Forward $+10,000$ & $\mathrm{U}$ & TGATTTGAGGATTATGTGTATTGGATTT & \multirow{2}{*}{$99.04 \%$} \\
\hline & & Reverse $+10,069$ & $\mathrm{U}$ & ССААТTТСТTТТТССАТТСТССАТАС & \\
\hline & & Forward +9995 & M & CGAGGATTACGTGTATTGGATTTTAA & $103.13 \%$ \\
\hline & & Reverse $+10,065$ & M & TTTCTTTTTCCATTCTCCGTACAATA & \\
\hline & \multirow{4}{*}{ CpG 4} & Forward $+11,606$ & $\mathrm{U}$ & AGGAGTGTATGTTTTTTAAGGTTTTAGATG & \multirow{2}{*}{$96.42 \%$} \\
\hline & & Reverse $+11,701$ & $\mathrm{U}$ & AACAAAACTACTAAAAATTAAATAACTTCCCA & \\
\hline & & Forward $+11,606$ & $\mathrm{M}$ & AGGAGTGTATGTTTTTTAAGGTTTTAGACG & \multirow{2}{*}{$98.73 \%$} \\
\hline & & Reverse $+11,701$ & M & ACGAAACTACTAAAAATTAAATAACTTCCCA & \\
\hline & \multirow{4}{*}{ CpG 5} & Forward $+12,857$ & $\mathrm{U}$ & GATTTGGATTTGTTGTTAAGGGTTTT & \multirow{2}{*}{$102.17 \%$} \\
\hline & & Reverse $+12,924$ & $\mathrm{U}$ & AACCAACACCCACCACTACCTAA & \\
\hline & & Forward $+12,859$ & M & TTCGGATTTGTCGTTAAGGGTT & $106.16 \%$ \\
\hline & & Reverse 12,927 & M & CCAACACCCACCGCTACC & \\
\hline & & Forward $+13,120$ & $\mathrm{U}$ & TTATTTGGATATGGGATAAGAGAGGG & $98.27 \%$ \\
\hline & $a_{n} C$ & Reverse $+13,216$ & $\mathrm{U}$ & CACCATCTAAAATAATACTACTTTCTTTCACTTAT & \\
\hline & Cpub & Forward $+13,120$ & $\mathrm{M}$ & TTATTTGGATACGGGATAAGAGAGG & $102.64 \%$ \\
\hline & & Reverse $+13,219$ & $\mathrm{M}$ & CGTCTAAAATAATACTACTTTCTTTCGCTT & \\
\hline
\end{tabular}

* The qPCR amplification efficiency is calculated based on the slope of the standard curve https://www.lifetechnologies.com/us/en/home/brands/thermo-scientific/molecular-biology/molecular-biologylearning-center/molecular-biology-resource-library/thermo-scientific-web-tools/qpcr-efficiency-calculator.html. Slopes between -3.1 and -3.6 giving reaction efficiencies between 90 and $110 \%$ are typically acceptable.

\subsection{Gene Expression}

Total RNA was extracted using previously published methods [20]. Briefly, frozen liver tissue was ground in liquid nitrogen and the Direct-zol ${ }^{\mathrm{TM}}$ RNA MiniPrep kit (Zymo Research) was used for RNA isolation. RT-PCR was performed using the High Capacity cDNA Reverse Transcription Kit (Applied Biosystems) and incubated in a 2720 Thermal Cycler (Applied Biosystems). A serially diluted standard curve was created, and qPCR was carried out using Power SYBR ${ }^{\circledR}$ Green Master Mix (Life 
Technologies) run in a StepOnePlus ${ }^{\mathrm{TM}}$ Real-Time PCR System. All primers were designed using Vector NTI (Life Technologies) and manufactured by Integrated DNA Technologies. Information regarding primers for gene expression is detailed in Table 2.

Table 2. Gene expression primers.

\begin{tabular}{|c|c|c|c|c|c|}
\hline Gene & Ensembl ID & Common Name & Position & Primers $\left(5^{\prime} \rightarrow 3^{\prime}\right)$ & Efficiency * \\
\hline \multirow{2}{*}{ Acacb } & \multirow{2}{*}{ ENSRNOT00000078868.1 } & \multirow{2}{*}{$\begin{array}{c}\text { Acetyl-CoA } \\
\text { Carboxylase Beta }\end{array}$} & Forward +1081 & ACCCCAAACTTCCAGAGC & \multirow{2}{*}{$105.70 \%$} \\
\hline & & & Reverse +1189 & TGGGCTACAATGGTGGAG & \\
\hline \multirow{2}{*}{ Acox3 } & \multirow{2}{*}{ ENSRNOT00000049798.3 } & \multirow{2}{*}{$\begin{array}{c}\text { Acyl-CoA Oxidase 3, } \\
\text { Pristanoyl }\end{array}$} & Forward +1553 & TGACTGGTTGGACTCAGA & \multirow{2}{*}{$94.56 \%$} \\
\hline & & & Reverse +1629 & TCTGATGACTCTCTCGGA & \\
\hline \multirow{2}{*}{ Actb } & \multirow{2}{*}{ ENSRNOT00000042459.4 } & \multirow{2}{*}{ Actin Beta } & Forward +451 & GAGACCTTCAACACCCCAGC & \multirow{2}{*}{$104.67 \%$} \\
\hline & & & Reverse +526 & CAGTGGTACGACCAGAGGCA & \\
\hline \multirow{2}{*}{ Acvr1c } & \multirow{2}{*}{ ENSRNOT00000059280.4 } & \multirow{2}{*}{$\begin{array}{l}\text { Activin A Receptor } \\
\text { Type 1C }\end{array}$} & Forward +511 & TGATTTATGATGCCACTGCC & \multirow{2}{*}{$100.24 \%$} \\
\hline & & & Reverse +586 & ATTGTCCTTGCGATGGTTCT & \\
\hline \multirow{2}{*}{ Adh1 } & \multirow{2}{*}{ ENSRNOT00000036993.4 } & \multirow{2}{*}{$\begin{array}{c}\text { Alcohol } \\
\text { Dehydrogenase } 1\end{array}$} & Forward +257 & ATGAAGGAGTTGGGATAG & \multirow{2}{*}{$100.37 \%$} \\
\hline & & & Reverse +318 & ATCACCTGTTCTTACGCT & \\
\hline \multirow{2}{*}{ Adh5 } & \multirow{2}{*}{ ENSRNOT00000016891.6 } & Alcohol & Forward +637 & GTGTGTCTGATTGGATGTGG & $117.98 \%$ \\
\hline & & Dehydrogenase 5 & Reverse +700 & TGACCTTGGCAGTGTTGA & $117.98 \%$ \\
\hline Adh7 & ENSRNOT00000015870.4 & Alcohol & Forward +262 & GAAGCAGTTGGGATTGTGGAGA & $108.18 \%$ \\
\hline Aan' & ENSSKIVU I 10000000158/0.4 & Dehydrogenase 7 & Reverse +328 & TCACTTTGTCACCTGGTCTCACTG & $108.18 \%$ \\
\hline Cacng8 & ENSRNOT00000078444.1 & Calcium Voltage-Gated & Forward +297 & CTGCGTGAAGATCAACCACT & $108.34 \%$ \\
\hline Cacilgo & ENSKRNOIOUOUOU/8444.1 & $\begin{array}{l}\text { Channel Auxiliary } \\
\text { Subunit Gamma } 8 \\
\end{array}$ & Reverse +395 & ATAGGAAAGATGCTGGAGGC & $108.34 \%$ \\
\hline Cpt2 & ENSRNOT00000016954.3 & & Forward +310 & GACACCATGAAGAGATACCT & $107.28 \%$ \\
\hline Cpic & 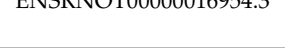 & Palmitoyltransferase 2 & Reverse +387 & ACACAACGCTTCTGTTCT & $107.20 \%$ \\
\hline Dapk3 & ENSRNOT00000027634.4 & Death Associated & Forward +624 & TTCGTCGCCCCTGAGATTGTAA & $103.21 \%$ \\
\hline Dapko & 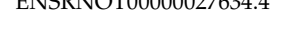 & Protein Kinase 3 & Reverse +685 & ATGACGCCGATGCTCCACATAT & $103.21 \%$ \\
\hline Dcc & ENSRNOT00000064947.3 & DCC Netrin 1 Receptor & Forward +1144 & GTGGCTGAAAATGAGGCTGGC & $100.76 \%$ \\
\hline & & & Reverse +1208 & ATGGCAGGCTTGGGGACAA & \\
\hline Enox1 & ENSRNOT00000074868.2 & Ecto-NOX & Forward +167 & TTGAGAGCATCGCACAGTGT & $93.82 \%$ \\
\hline & & $\begin{array}{l}\text { Disulfide-1nol } \\
\text { Exchanger } 1\end{array}$ & Reverse +239 & ATGCTCCСCAAACCATCA & \\
\hline Fads2 & ENSRNOT00000059280.4 & Fatty Acid Desaturase 2 & Forward +711 & CGTGTTTGTCCTTGGAGAGTGGC & $108.89 \%$ \\
\hline Fraasz & 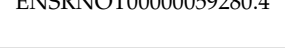 & 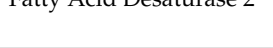 & Reverse +790 & CATGCTGGTGGTTGTAGGGCA & $108.89 \%$ \\
\hline Flnb & ENSRNOT00000066546.1 & Filamin B & Forward +353 & GCTGGAGAATGTGTCTGT & $108.69 \%$ \\
\hline FInD & 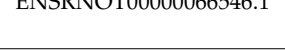 & Filamin D & Reverse +422 & ACTGTCAATGGACACGAG & $108.69 \%$ \\
\hline Foxo1 & ENSRNOT00000018244.5 & Forkhead Box O1 & Forward +994 & AGGATAAGGGCGACAGCAACAG & $102.12 \%$ \\
\hline FOxO1 & 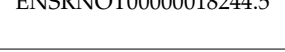 & Forkneaa box U1 & Reverse +1056 & GGGACAGATTGTGGCGAATTG & $102.12 \%$ \\
\hline Fzd2 & ENSRNOT00000032944.2 & Frizzled Class Receptor 2 & Forward +818 & TTTTGCCCGTCTCTGGAT & $93.13 \%$ \\
\hline FZd2 & ENSRINUIOU000032944.2 & 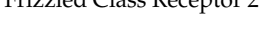 & Reverse +889 & TAGGTGGTGACCGTGAAGAA & $93.13 \%$ \\
\hline Gapdh & ENSRNOT00000050443.4 & Glyceraldehyde-3- & Forward +220 & СТCTACCCACGGCAAGTTCAACG & $100.39 \%$ \\
\hline & & Dehydrogenase & Reverse +311 & CTCGCTCCTGGAAGATGGTGATG & \\
\hline Hk3 & ENSRNOT00000031935.2. & Hexokinase 3 & Forward +973 & ССCTGGTTCCTGGTGCTCAG & $119.40 \%$ \\
\hline & & & Reverse +1050 & CCAGCACCAGCCTTACCAGC & \\
\hline Igfr1 & ENSRNOT00000019267 6 & Insulin Like Growth & Forward +2239 & CTGAGAGGAGGCGGAGAGATG & $109.39 \%$ \\
\hline & & & Reverse +2304 & TGTTCCTGCTTCGGCTGG & \\
\hline Ill1r1 & ENSRNOT00000019673.4 & Interleukin 1 Receptor & Forward +393 & GGGTTCATTTGTCTCATTGTGC & $101.20 \%$ \\
\hline IIITI & 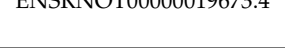 & Type 1 & Reverse +465 & TGACCTCATTTGGATACTCCGT & $101.20 \%$ \\
\hline Irs2 & ENSRNOT00000032918.6 & Insulin Receptor & Forward +3373 & CTTGAAGCGGCTAAGTCT & $109.86 \%$ \\
\hline IrS2 & ENSSKN IIU00000032918.6 & Substrate 2 & Reverse +3435 & TGGCTGACTTGAAGGAAG & $109.86 \%$ \\
\hline Lpin3 & ENSRNOT00000022403.5 & Lipin 3 & Forward +578 & СССТCATCGCAGCCTAAAGACAT & $108.38 \%$ \\
\hline & & & Reverse +657 & AGGTCAGCAGATGAAAGGTTGGC & \\
\hline Map3k5 & ENSRNOT00000051496.6 & Mitogen-Activated & Forward +455 & GTTTTTACAACGCTGACATCGC & $105.77 \%$ \\
\hline & & $\begin{array}{l}\text { Protein Kinase Kinase } \\
\text { Kinase } 5\end{array}$ & Reverse +525 & ATGATAAAACAGGGAAGGCTGC & \\
\hline Mapk3 & ENSRNOT00000087625.1 & Mitogen-Activated & Forward +618 & CACTGGCTTTCTTACCGAGT & $111.47 \%$ \\
\hline & & & Reverse +696 & GGTGTAGCCCTTGGAGTTAA & \\
\hline
\end{tabular}


Table 2. Cont.

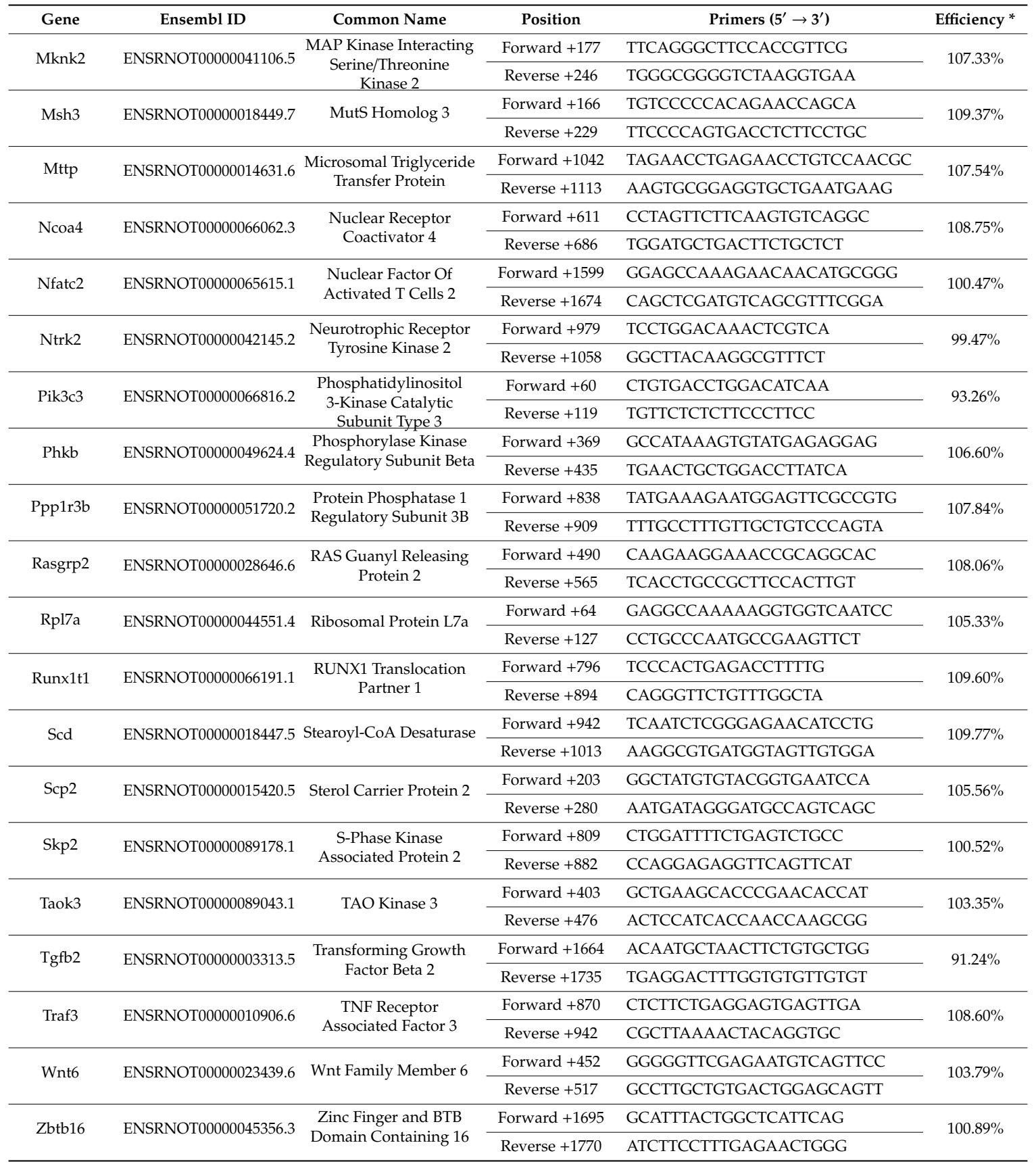

* The qPCR amplification efficiency is calculated based on the slope of the standard curve https://www.lifetechnologies.com/us/en/home/brands/thermo-scientific/molecular-biology/molecular-biology-

learning-center/molecular-biology-resource-library/thermo-scientific-web-tools/qpcr-efficiency-calculator.html.

Slopes between -3.1 and -3.6 giving reaction efficiencies between 90 and $110 \%$ are typically acceptable.

\subsection{Analysis of Intergenic DMRs}

In previous analyses, DMRs that are not located within close proximity of genes are often ignored. We attempted to uncover functions for these DMRs by using previously published high throughput chromatin contact data (Hi-C) [27]. Such chromatin contact maps are not publicly available for rat tissue, thus we examined only DMRs that were conserved between species using the phastCons9way track from Genome Browser. Conservation scores range from 0 to 1 , where 1 denotes perfect sequence alignment and high conservation. For our analysis, we only considered DMRs that had a mean alignment score $>0.5$ over the 500 bp bin. 
Next, the analogous region from the Rn4 genome build was identified in the $\mathrm{Hg} 38$ genome. We used the 3D Genome Browser to visualize Hi-C data from human liver tissue [27,28]. In particular, we examined each of the $500 \mathrm{bp}$ DMRs and the $1 \mathrm{mb}$ region flanking either side of the region. We then located the topologically associated domain (TAD) which contained the DMR. Genes within the TAD were considered to have contact with the nearby DMR. Those genes were selected for gene ontology and pathway analyses.

\subsection{Statistical Analysis}

For body weight, food intake, MSP, and gene expression, all pairwise comparisons between groups were made using two-tailed t-tests. For pathway analysis, significant enrichment was determined using the Benjamini-Hochberg FDR $p$-value. All statistical analysis was performed in R (version 3.1.2).

\section{Results}

\subsection{Offspring Phenotype}

Male Sprague-Dawley rats were divided into two groups and exposed to either a LF or a HF diet for seven weeks during gestation and lactation ( $n=10$ /group; Figure 1A). After weaning (postnatal week three), all animals were given a HF dietary challenge that mimicked an obesogenic western diet. Animals were fed the HF diet for nine weeks and sacrificed at 12 weeks of age. Across the nine weeks of post-weaning feeding, there was no difference in food intake between the groups (Figure 1B). Additionally, body weights were consistent between groups, suggesting that maternal diet was insufficient to compensate for HF-induced postnatal weight gain (Figure 1C,D).

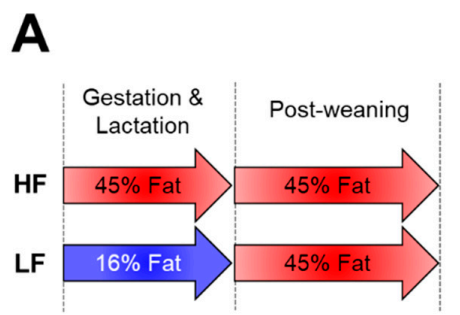

C

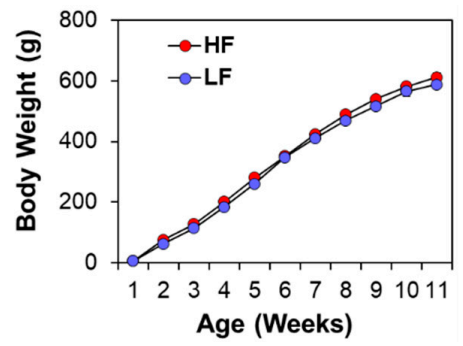

B

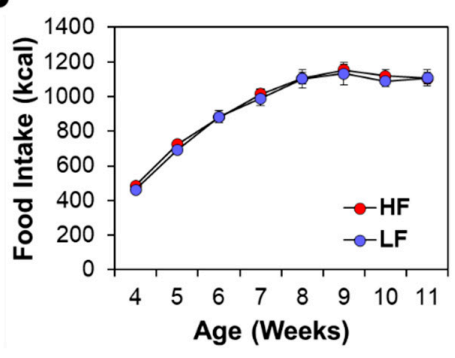

D

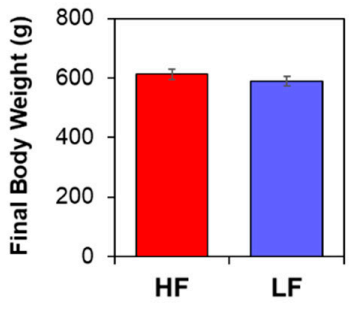

Figure 1. Maternal diet did not impact postnatal phenotype when followed by a high-fat (HF) diet. (A) Male Sprague-Dawley rats were given either a HF or low-fat (LF) diet during gestation and lactation (seven weeks). Both groups were given a HF diet after weaning (nine weeks; $n=10 /$ group). (B) Caloric intake after weaning did not differ between the two groups. (C) Postnatal, and (D) final, body weight did not differ between groups.

\subsection{DNA Methylation}

Despite the lack of phenotypic differences, we hypothesized that epigenetic differences might still exist. Methylated DNA was measured using MeDIP-seq and unmethylated DNA was measured with MRE-seq. Combining the two methods, 1,419 differentially methylated regions (DMRs) were identified between groups (Figure 2A). Of these, 534 (37.6\%) were more highly methylated in the HF group, 
while 885 (62.4\%) were more highly methylated in the LF group (Figure 2B). Next, analysis of the genomic location of the DMRs revealed that 827 (58.3\%) were located in intergenic regions (not within $1,500 \mathrm{bp}$ of a gene), 524 (36.9\%) were within the gene body (including intronic and exonic sequences), $48(3.4 \%)$ were in a promoter (within 1,500 bp upstream of the TSS), and $45(3.2 \%)$ were downstream of a gene (within $1500 \mathrm{bp}$ downstream of the TES) (Figure 2C). We next examined DMR location relative to $\mathrm{CpG}$ islands and saw that more than twice as many DMRs were located within CpG shores $(n=435$, $30.7 \%$ ) than in islands themselves ( $n=177,12.5 \%$, Figure 2D).
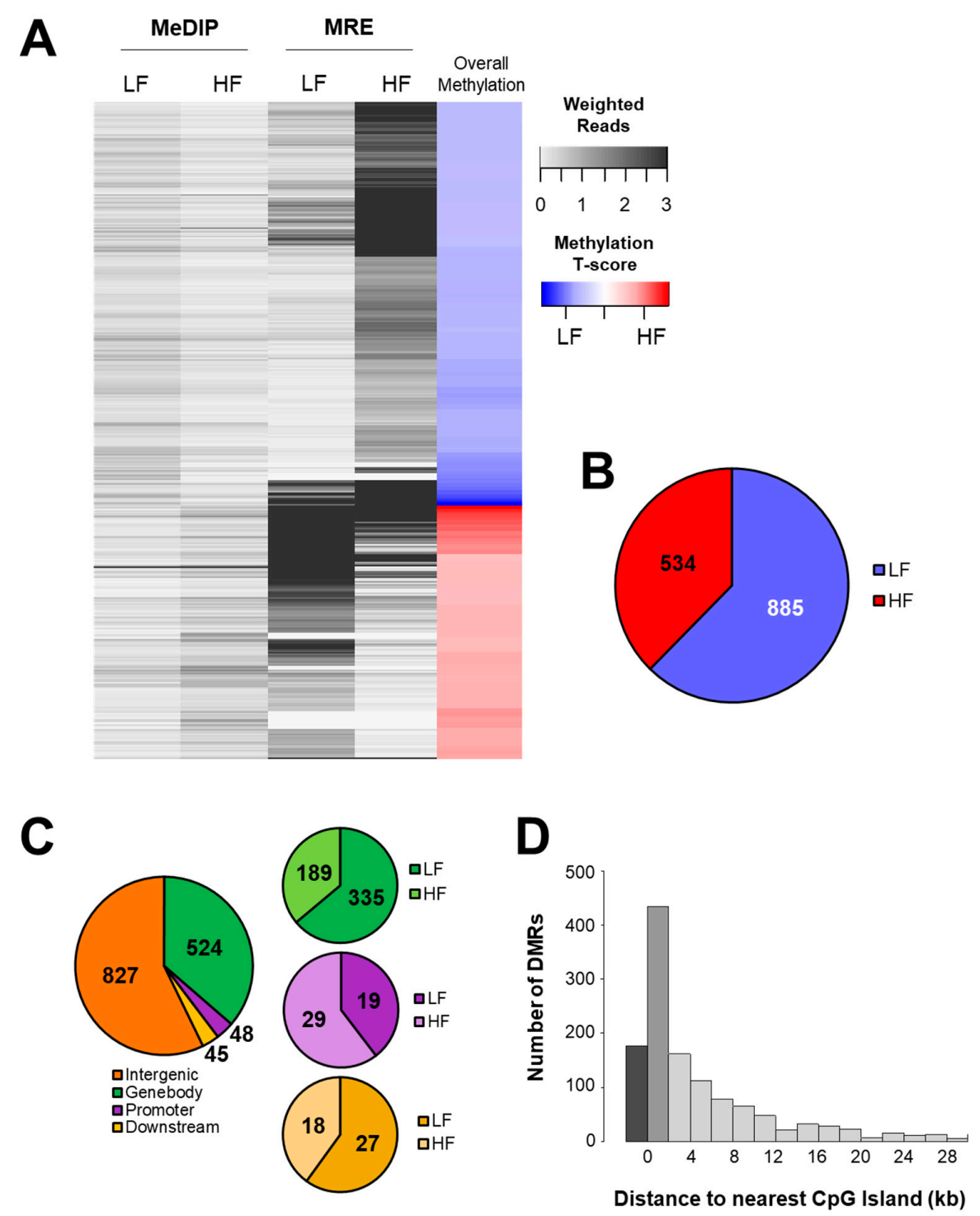

Figure 2. Maternal diet altered hepatic DNA methylation. (A) MeDIP-seq and MRE-seq were performed to quantify genome-wide DNA methylation. (B) Sequencing revealed 1,419 differentially methylated regions (DMRs) between groups (false discovery rate, FDR, $p$-value $<0.05)$, including $534(37.6 \%)$ that were more highly methylated in the HF group and 885 (62.4\%) that were more highly methylated in the LF group. (C) DMR position relative to genomic features, including intergenic regions, gene bodies, promoters, and downstream regions. (D) DMR location relative to CpG islands and shores.

DNA methylation was validated using MSP. First, we tested one DMR located within the Myh7b gene that was identified to be more highly methylated in the LF group by MeDIP-seq and MRE-seq (Figure 3A-D). MSP was performed on six CpG sites within the DMR. Although one site was not differentially methylated, two of the sites were higher but not significantly hypermethylated in the LF group $(p<0.1)$ and three were significantly more methylated in the LF group $(p<0.05$, Figure 3E). 
Furthermore, the average DNA methylation across all six sites was significantly higher in the LF group $(p=0.0089$, Figure 3F). Negative control was also performed on four CpG sites within the Gpam gene (Figure 3G). Four CpGs that were not computationally identified by MeDIP and MRE analysis were examined with MSP (Figure 3H,I). Neither the individual sites nor the average over the region showed differential methylation (Figure 3J,K). Findings here and in our previous work demonstrate the validity of combined MeDIP-seq and MRE-seq analysis [16,20].
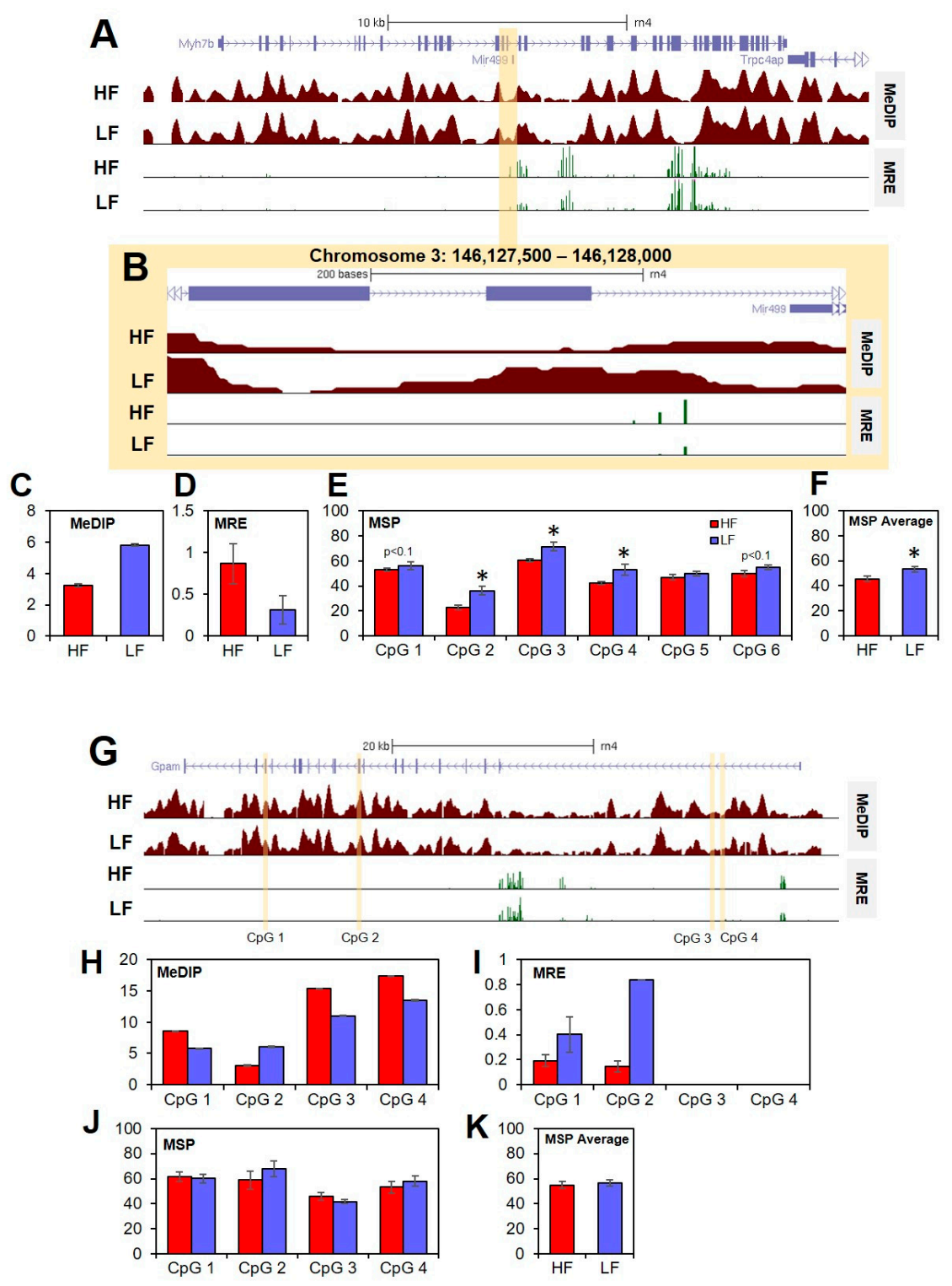

Figure 3. Methylation Specific PCR validates MeDIP-seq and MRE-seq findings. (A) Analysis of MeDIP-seq and MRE-seq identified a significant DMR within the gene body of the Myh7b gene (FDR p-value < 0.05). (B) The DMR spanned exon 17, intron 17/18, exon 18, and part of intron 18/19. (C) MeDIP-seq and (D) MRE-seq values are given as average reads \pm standard error of the mean (SEM). (E) MSP was used to measure DNA methylation at six individual CpG sites within the DMR. (F) MSP quantities were averaged over the six sites. MSP values are reported as \% DNA methylation \pm SEM (* $p<0.05)$. (G) Among regions that were not significantly differentially methylated, four CpGs were chosen in the Gpam gene body as negative controls. (H) MeDIP-seq and (I) MRE-seq values are given as average reads \pm SEM. (J) MSP was used to measure DNA methylation at the four CpG sites and (K) methylation was averaged over the four sites. MSP values are reported as $\%$ DNA methylation \pm SEM $(* p<0.05)$. 
In order to understand the functional relevance of the gene-associated DMRs, gene ontology (GO) and KEGG pathway analyses were performed. We found that DMGs tended to cluster in processes involved in ion binding, cell morphogenesis, ion channels, and neuronal development (Table 3). Additionally, we found that the biosynthesis of unsaturated fatty acids pathway was most highly enriched for differential methylation, while pathways in cancer contained the greatest number of differentially methylated genes (Figure 4). Interestingly, we found that other metabolic and cancer pathways were also enriched, including the insulin signaling, colorectal cancer, and mitogen-activated protein kinase (MAPK) signaling pathways.

Table 3. Gene ontology clustering.

\begin{tabular}{|c|c|c|c|c|}
\hline GO Number & GO Annotation & Count & Fold Enrichment & FDR $p$-Value \\
\hline \multicolumn{5}{|c|}{ Annotation Cluster 1 (Enrichment Score: 6.24) } \\
\hline GO:0046872 & Metal ion binding & 111 & 1.54 & $2.37 \times 10^{-4}$ \\
\hline GO:0043167 & Ion binding & 113 & 1.52 & $1.70 \times 10^{-4}$ \\
\hline GO:0043169 & Cation binding & 111 & 1.52 & $1.61 \times 10^{-4}$ \\
\hline \multicolumn{5}{|c|}{ Annotation Cluster 2 (Enrichment Score: 5.24) } \\
\hline GO:0000902 & Cell morphogenesis & 26 & 3.02 & 0.0013 \\
\hline GO:0032989 & Cellular component morphogenesis & 26 & 2.73 & 0.0045 \\
\hline GO:0000904 & Cell morphogenesis involved in differentiation & 20 & 3.27 & 0.0046 \\
\hline \multicolumn{5}{|c|}{ Annotation Cluster 3 (Enrichment Score: 4.57 ) } \\
\hline GO:0005216 & Ion channel activity & 24 & 2.83 & 0.0016 \\
\hline GO:0005261 & Cation channel activity & 20 & 3.18 & 0.0017 \\
\hline GO:0022838 & Substrate specific channel activity & 24 & 2.75 & 0.0018 \\
\hline GO:0015267 & Channel activity & 24 & 2.65 & 0.0028 \\
\hline GO:0022803 & Passive transmembrane transporter activity & 24 & 2.65 & 0.0028 \\
\hline GO:0022836 & Gated channel activity & 20 & 2.95 & 0.0033 \\
\hline \multicolumn{5}{|c|}{ Annotation Cluster 4 (Enrichment Score: 4.18 ) } \\
\hline GO:0048667 & $\begin{array}{l}\text { Cell morphogenesis involved in neuron } \\
\text { differentiation }\end{array}$ & 19 & 3.63 & 0.0029 \\
\hline GO:0000904 & Cell morphogenesis involved in differentiation & 20 & 3.27 & 0.0046 \\
\hline GO:0007409 & Axonogenesis & 17 & 3.61 & 0.0056 \\
\hline GO:0048666 & Neuron development & 23 & 2.62 & 0.014 \\
\hline GO:0048812 & Neuron projection morphogenesis & 17 & 3.12 & 0.021 \\
\hline GO:0031175 & Neuron projection development & 19 & 2.75 & 0.034 \\
\hline GO:0048858 & Cell projection morphogenesis & 17 & 2.82 & 0.045 \\
\hline GO:0032990 & Cell part morphogenesis & 17 & 2.71 & 0.066 \\
\hline \multicolumn{5}{|c|}{ Annotation Cluster 5 (Enrichment Score: 4.08) } \\
\hline GO:0022836 & Gated channel activity & 20 & 2.95 & 0.0033 \\
\hline GO:0005244 & Voltage-gated ion channel activity & 15 & 3.47 & 0.0062 \\
\hline GO:0022832 & Voltage-gated channel activity & 15 & 3.47 & 0.0062 \\
\hline \multicolumn{5}{|c|}{ Annotation Cluster 6 (Enrichment Score: 3.45) } \\
\hline GO:0051960 & Regulation of nervous system development & 17 & 2.95 & 0.036 \\
\hline GO:0060284 & Regulation of cell development & 17 & 2.87 & 0.044 \\
\hline GO:0045664 & Regulation of neuron differentiation & 14 & 3.31 & 0.042 \\
\hline GO:0050767 & Regulation of neurogenesis & 15 & 2.86 & 0.086 \\
\hline
\end{tabular}




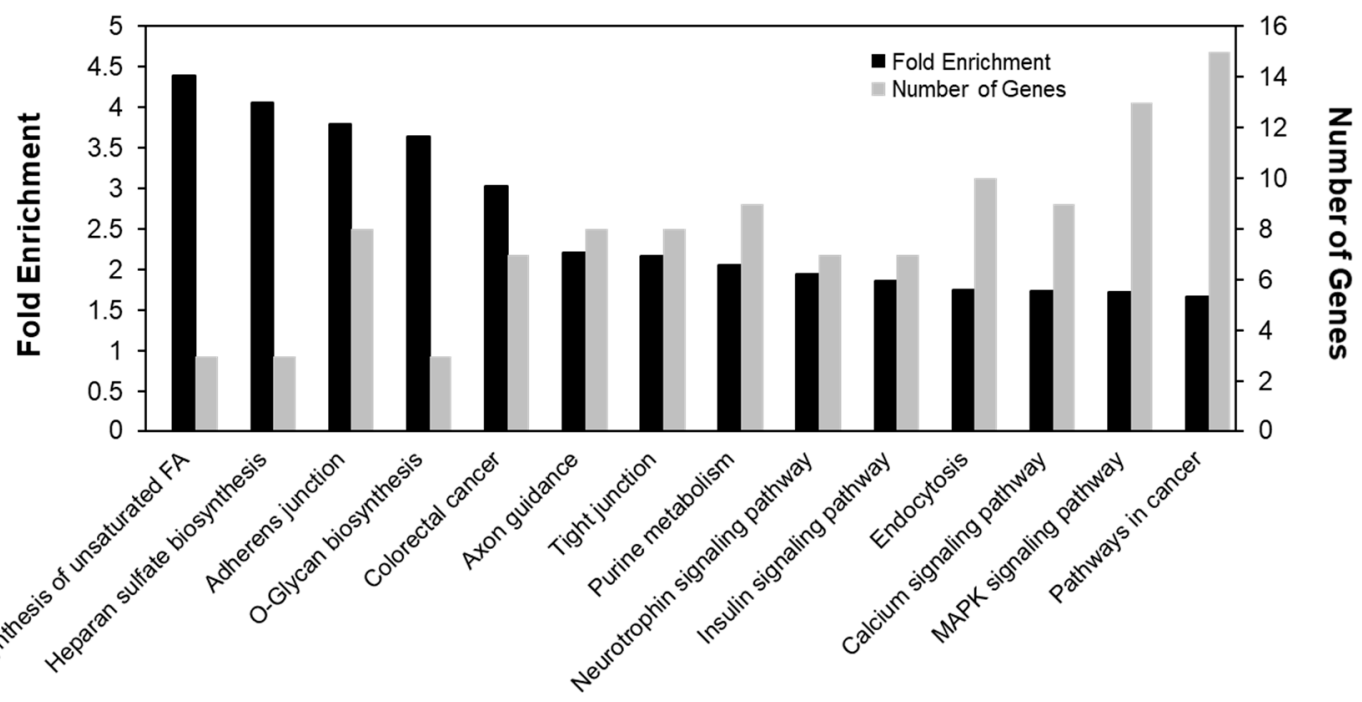

\section{KEGG Pathway}

Figure 4. Differential methylation was most enriched in metabolic and cancer-related pathways.

\subsection{Gene Expression}

Given the enrichment of differential methylation in cancer and metabolic genes, qPCR was utilized to measure gene expression of 31 differentially methylated genes in those pathways. Details regarding the genomic location and methylation levels of the gene-associated DMRs can be found in Table 4 . We found two differentially expressed genes, including Map3k5 and $\operatorname{Igfl} 1 r(p=0.030$ and $p=0.026$, respectively; Figure 5). Both Igf1r and Map3k5 were related to cancer and metabolism. Both Map3k5 and Igf1 $r$ were more highly expressed in the LF group compared to the HF group.

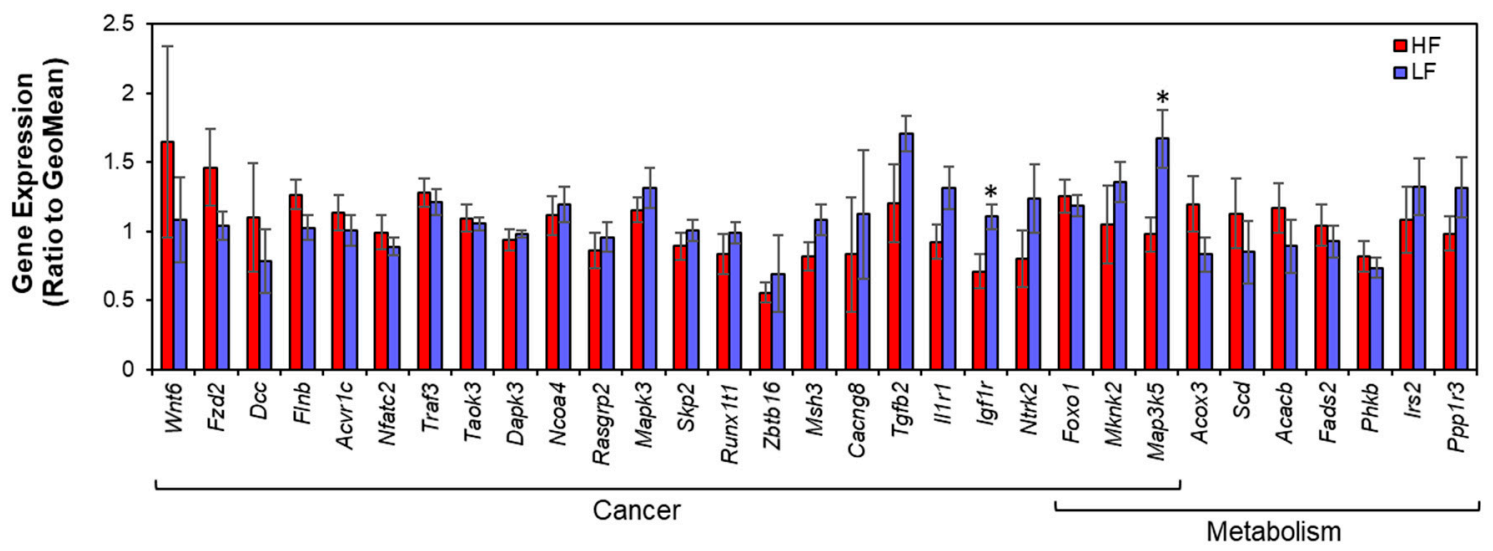

Figure 5. Gene expression in cancer and metabolism genes. Gene expression values are normalized to the geometric mean of Actb, Gapdh, and Rpl7a. ${ }^{*} p<0.05$. 
Table 4. DMR description.

\begin{tabular}{|c|c|c|c|c|c|c|c|c|c|}
\hline Gene & Function & Chromosome & Location & $\begin{array}{c}\text { Genomic } \\
\text { Feature }\end{array}$ & HF MeDIP & LF MeDIP & HF MRE & LF MRE & Conservation \\
\hline ACVR1C & Cancer & 3 & $40041000-40041500$ & Intron $3 / 8$ & $2.33(0.89)$ & $2.58(1.02)$ & $1.64(0)$ & 0 & $0.0040(0.016)$ \\
\hline CACNG2 & Cancer & 7 & $116000000-116000500$ & Intron $1 / 3$ & $8.27(3.47)$ & $12.26(4.78)$ & $0.74(0.42)$ & $0.31(0.24)$ & $0.77(0.36)$ \\
\hline CACNG8 & Cancer & 1 & $64069000-64069500$ & Exon $4 / 4$ & $2.56(1.15)$ & $2.00(0.82)$ & $0.27(0)$ & $6.07(0)$ & $0.18(0.34)$ \\
\hline DAPK3 & Cancer & 7 & 10009000-10009500 & Exon $7 / 9$ & $12.89(6.18)$ & $18.09(10.40)$ & $1.10(0.68)$ & $0.14(0)$ & $0.38(0.45)$ \\
\hline DCC & Cancer & 18 & $69043500-69044000$ & Intron $1 / 28$ & $8.56(3.39)$ & $21.00(9.64)$ & $3.68(1.51)$ & $2.16(1.46)$ & $0.0054(0.0087)$ \\
\hline FLNB & Cancer & 15 & $19052000-19052500$ & Intron $1 / 44$ & $4.89(2.41)$ & $5.98(2.59)$ & $2.06(2.03)$ & $0.51(0.58)$ & $0.014(0.017)$ \\
\hline FZD2 & Cancer & 10 & 91707500-91708000 & Promoter & $6.27(3.41)$ & $1.40(0.55)$ & $0.27(0.21)$ & $0.95(0.71)$ & $0.061(0.094)$ \\
\hline IGF1R & Cancer & 1 & $122713500-122714000$ & Intron $1 / 20$ & $4.31(1.20)$ & $3.10(1.81)$ & $0.71(0)$ & $1.39(0.99)$ & $0.0057(0.011)$ \\
\hline IL1R1 & Cancer & 9 & 39589500-39590000 & Intron $1 / 10$ & $7.39(4.28)$ & $4.33(1.62)$ & $0.12(0)$ & $1.00(0.93)$ & $0.0053(0.0099)$ \\
\hline MAP3K5 & Cancer & 1 & $15307000-15307500$ & Intron $8 / 12$ & $1.88(0.83)$ & $4.86(2.15)$ & $7.37(0)$ & $1.13(0)$ & $0.018(0.050)$ \\
\hline MSH3 & Cancer & 2 & $22480500-22481000$ & Intron $20 / 23$ & $10.93(4.44)$ & $4.08(2.34)$ & $0.42(0.42)$ & $1.60(0.93)$ & $0.0050(0.014)$ \\
\hline NCOA4 & Cancer & 16 & $7641000-7641500$ & Promoter & $12.59(3.16)$ & $5.25(2.38)$ & $0.27(0.085)$ & $1.10(0.84)$ & $0.0026(0.0036)$ \\
\hline NFATC2 & Cancer & 3 & 159682000-159682500 & Intron $8 / 9$ & $10.58(5.74)$ & $3.06(1.24)$ & $1.07(0)$ & $1.73(2.32)$ & $0.015(0.0038)$ \\
\hline NTRK2 & Cancer & 17 & $11700500-11701500$ & Intron $12 / 13$ & $7.81(3.75)$ & $17.72(8.57)$ & $4.31(3.07)$ & $1.21(1.92)$ & $0.28(0.41)$ \\
\hline RASGRP2 & Cancer & 1 & 209198000-209198500 & Intron $15 / 16$ & $4.29(2.91)$ & $6.10(4.07)$ & $0.85(0.14)$ & $0.19(0)$ & $0.22(0.33)$ \\
\hline RUNX1T1 & Cancer & 5 & $28230500-28231000$ & Exon $1 / 11$ & $2.63(1.09)$ & $1.00(0)$ & $1.70(1.81)$ & $8.70(11.88)$ & $0.31(0.43)$ \\
\hline SKP2 & Cancer & 2 & $58774500-58775000$ & Exon $8 / 10$ & $8.21(4.43)$ & $17.98(10.69)$ & $0.93(1.08)$ & 0 & $0.13(0.30)$ \\
\hline TAOK3 & Cancer & 12 & $40571000-40571500$ & Intron $5 / 19$ & $12.23(7.54)$ & $7.64(3.88)$ & $1.51(2.00)$ & $4.16(5.87)$ & $0.23(0.41)$ \\
\hline TGFB2 & Cancer & 13 & $102723000-102723500$ & Intron $6 / 7$ & $10.45(6.36)$ & $4.61(2.68)$ & $0.24(0)$ & $3.47(0.13)$ & $0.39(0.47)$ \\
\hline TRAF3 & Cancer & 6 & $135924000-135924500$ & Promoter & $5.27(2.45)$ & $1.50(0.71)$ & $0.47(0.57)$ & $10.45(21.93)$ & $0.036(0.073)$ \\
\hline WNT6 & Cancer & 9 & $74115500-74117500$ & Intron $3 / 3$ & $8.30(6.35)$ & $15.22(7.88)$ & $3.40(4.52)$ & $3.54(5.89)$ & $0.26(0.43)$ \\
\hline ZBTB16 & Cancer & 8 & $52035000-52036000$ & Intron $2 / 6$ & $5.24(2.69)$ & $7.58(2.93)$ & $4.00(0.63)$ & $0.70(0.30)$ & $0.45(0.49)$ \\
\hline FOXO1 & Cancer/Metabolism & 2 & 141195500-141196000 & Intron $1 / 2$ & $4.84(2.03)$ & $1.33(0.58)$ & $0.18(0.084)$ & $1.31(0.27)$ & $0.013(0.026)$ \\
\hline MAPK3 & Cancer/Metabolism & 1 & $185936000-185936500$ & Exon $2 / 10$ & $7.00(3.22)$ & $13.88(6.77)$ & $8.62(0)$ & $2.72(0)$ & $0.74(0.39)$ \\
\hline MKNK2 & Cancer/Metabolism & 7 & $10559000-10559500$ & Exon 14/14 & $8.85(3.70)$ & $14.22(6.72)$ & $3.20(2.54)$ & $0.98(0.97)$ & $0.32(0.42)$ \\
\hline
\end{tabular}


Table 4. Cont.

\begin{tabular}{|c|c|c|c|c|c|c|c|c|c|}
\hline Gene & Function & Chromosome & Location & $\begin{array}{l}\text { Genomic } \\
\text { Feature }\end{array}$ & HF MeDIP & LF MeDIP & HF MRE & LF MRE & Conservation \\
\hline ACACB & Metabolism & 12 & $43424500-43425000$ & Intron $30 / 58$ & $4.67(2.22)$ & $5.63(2.80)$ & $9.21(0.59)$ & $3.01(1.59)$ & $0.0020(0.0041)$ \\
\hline ACOX3 & Metabolism & 14 & $80781000-80781500$ & Intron $13 / 19$ & $15.48(9.69)$ & $3.00(1.58)$ & 0 & 0 & $0.0047(0.016)$ \\
\hline FADS2 & Metabolism & 1 & $212532500-212533000$ & Intron $4 / 10$ & $7.83(3.78)$ & $12.44(4.55)$ & $1.67(1.44)$ & $0.87(0.92)$ & $0.27(0.44)$ \\
\hline IRS2 & Metabolism & 16 & $83384000-83384500$ & Intron $1 / 1$ & $9.39(4.22)$ & $1.67(0.71)$ & $0.24(0.17)$ & $2.82(0.27)$ & $\begin{array}{l}0.00077 \\
(0.0032)\end{array}$ \\
\hline PHKB & Metabolism & 19 & $22453500-22454000$ & Intron $13 / 29$ & $4.43(2.08)$ & $11.92(5.76)$ & $0.91(0.18)$ & $0.19(0)$ & $0.038(0.12)$ \\
\hline PPP1R3B & Metabolism & 16 & $60562000-60562500$ & Intron $1 / 1$ & $4.08(2.56)$ & $1.00(0)$ & $0.49(0)$ & $6.85(0)$ & $0.026(0.076)$ \\
\hline SCD1 & Metabolism & 1 & $249463500-249464000$ & Intron $5 / 5$ & $10.82(4.11)$ & $16.68(5.85)$ & $1.89(1.58)$ & $0.47(0.40)$ & $0.012(0.037)$ \\
\hline
\end{tabular}

MeDIP and MRE values are given as average reads (standard deviation). Conservation denotes conservation score (standard deviation). 


\subsection{Intergenic $C p G s$}

Finally, we attempted to understand the impact of DNA methylation in regions that were not associated with particular genes. The majority of the identified DMRs were located in intergenic regions. Previously, such CpGs have been ignored. We hypothesized that even DMRs without obvious gene contact would impact expression via altering chromatic confirmation. Three-dimensional DNA dynamics have been studied in the human genome using chromatic capture techniques; however, these methods have not been performed in rat samples. Thus, we were only able to address the $42 \mathrm{CpG}$ sites that had a conservation score $>0.5$ (Figure $6 \mathrm{~A}$ ). From the $\mathrm{Rn} 4$ genome build, the analogous region was identified in the Hg38 genome. The DMR and the $1 \mathrm{mb}$ region flanking either side were queried for topologically associated domains (TADs) using Hi-C data from liver tissue (Figure 6B) [27]. KEGG Pathway and Gene Ontology analyses were performed on all genes that fell within a TAD containing a DMR (Figure 6C,D). Interestingly, these genes also had functions in metabolism, replicating the findings in the gene-associated DMRs.

We then measured the expression of ten metabolic genes associated with intergenic DMRs (Figure 7A). We found that Pik3c3 and Enox1 were more highly expressed in the HF group $(p=0.0028$ and $p=0.025$, respectively) while $A d h 5$ was more highly expressed in the LF group $(p=0.029)$. We then examined the DMRs within $1 \mathrm{mb}$ of each gene. Two DMRs were located upstream of the Pik3c3 TSS and were more methylated in the LF group as identified by MeDIP-seq and MRE-seq (Figure 7A). Four DMRs were located upstream of the Enox1 TSS. The two more distant DMRs $(-889,247$ and $-888,747 \mathrm{bp}$ upstream) were hypomethylated in the LF group, while the two more proximal DMRs ( $-472,747$ and $-373,747$ bp upstream) were hypermethylated in the LF group (Figure 7C). Two DMRs were located upstream of the Adh5 TSS. MeDIP-seq and MRE-seq showed that the more distant DMR $(-391,108 \mathrm{bp}$ upstream) was hypermethylated in the LF group while the more proximal DMR $(-170,108 \mathrm{bp}$ upstream) was hypomethylated in the LF group (Figure 7D). 


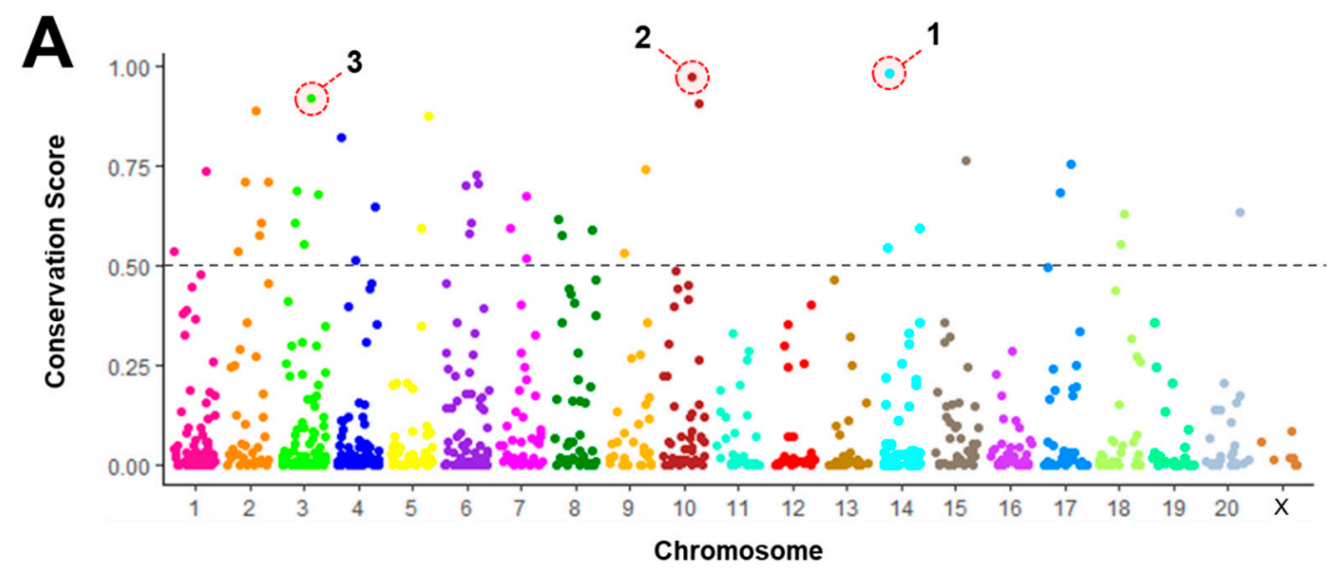

B

(1)

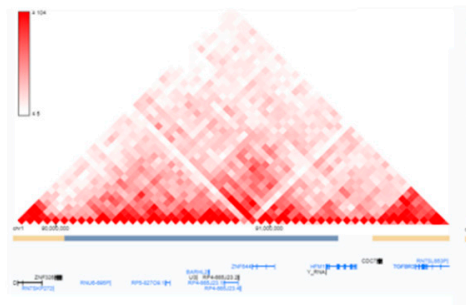

C

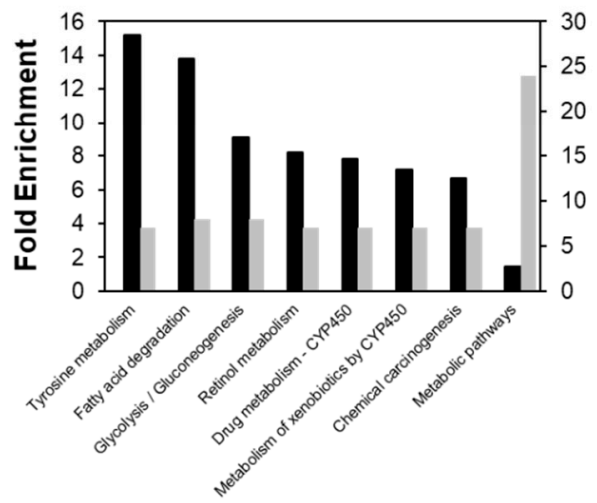

(2)

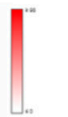

3

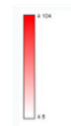

KEGG Pathway

Figure 6. Intergenic DMRs in conserved genomic regions were associated with metabolic genes through chromatin contacts. (A) The conservation score was calculated for every intergenic DMR and only those with scores $>0.5$ were considered for further analysis $(n=42)$. (B) Regions from the Rn4 genome build were aligned with the $\mathrm{Hg} 38$ genome and queried for chromatin contacts. As an example, contact maps are shown for the three DMRs with the highest conservation scores. Genes located within the DMR-associated topologically associated domain (TAD; gray bars) were used for functional analysis. (C) KEGG Pathway analysis and (D) functional clustering showed enrichment for metabolic processes. 


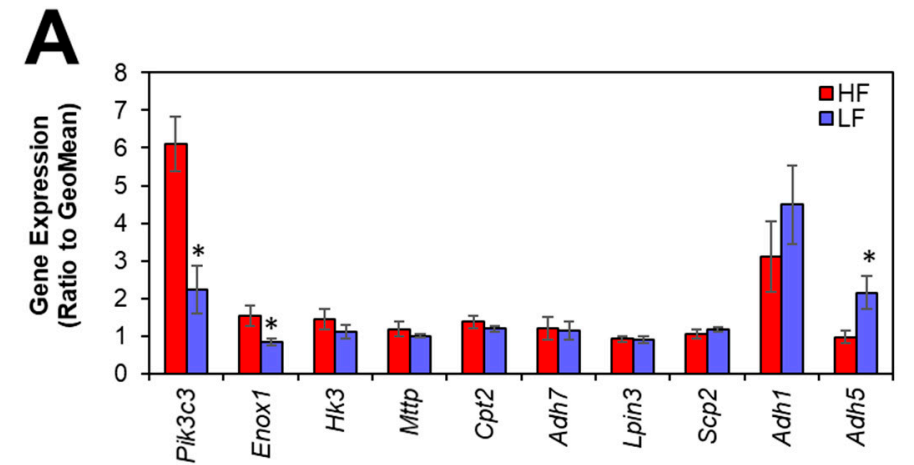

B

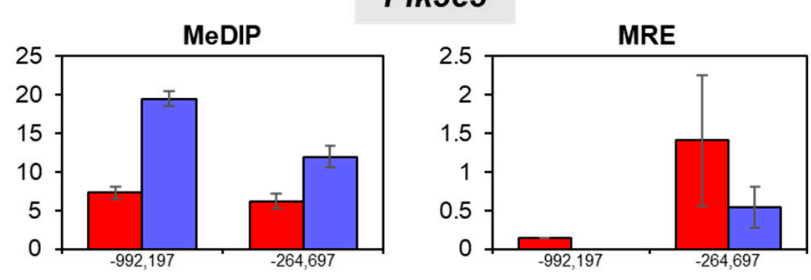

\section{Enox1}

C
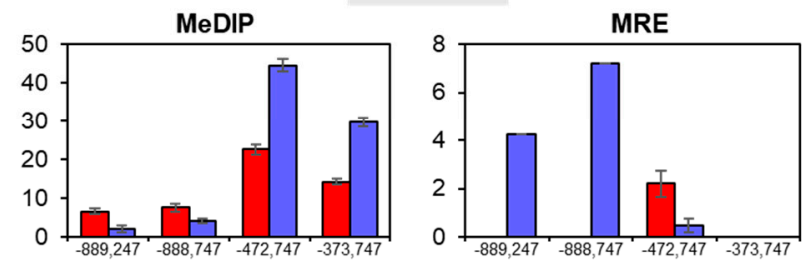

D

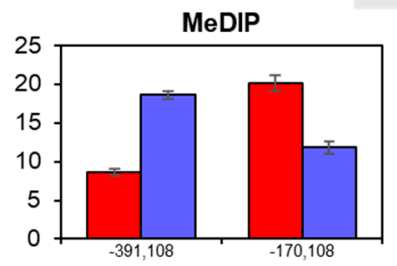

Adh5

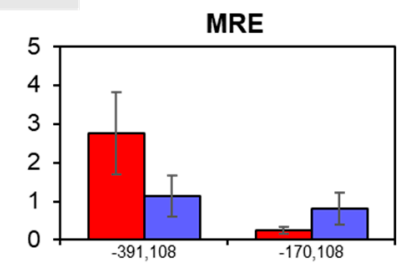

Figure 7. Expression of metabolic genes associated with intergenic DMRs. (A) Three genes were differentially expressed, including Pik3c3, Enox1, and Adh5. DMRs within $1 \mathrm{mb}$ upstream and downstream of the gene body are reported for (B) Pik3c3, (C) Enox1, and (D) Adh5. MeDIP-seq and MRE-seq values are presented as average reads \pm SEM.

\section{Discussion}

In this study, we investigated the role of maternal diet in hepatic epigenomic programming. Specifically, male Sprague-Dawley rats were fed either a LF or a HF diet during gestation and lactation. After weaning, all animals were given a HF diet challenge. After nine weeks on the post-weaning diet, there was no difference in body weight between groups; however, hepatic DNA methylation was changed at 1419 loci. Closer examination of the DMRs revealed enrichment for metabolic and cancer pathways. Gene expression analysis showed that only Map3k5 and Igflr were differentially expressed. Finally, we looked at the conserved intergenic DMRs and found that they were also located nearby differentially expressed metabolic genes. 
There was no difference in body weight and there were very few changes in gene expression between perinatal LF- and HF-exposed animals. Previous experiments have reported inconsistent results regarding body weight of animals that were given an obesogenic post-weaning diet preceded by different perinatal diets. After 14 weeks on a post-weaning HF diet, mice that had been exposed to a maternal HF diet had higher body weights than those exposed to a maternal LF diet $[29,30]$. Conversely, another study found that maternal dietary fat had no impact on body weight when male mouse offspring were fed a post-weaning HF diet for 17 weeks [31]. Finally, others have suggested that the impact of maternal diet is time dependent. In Sprague-Dawley rats, it was shown that perinatal diet did not change body weight after eight weeks of post-weaning HF feeding but did produce body weight differences after 16 weeks of post-weaning HF feeding [32]. In our case, we saw that the perinatal diet was not protective against HF-induced postnatal weight gain after nine weeks of HF feeding. Additionally, our study is limited because we did not consider any other metabolic parameters. Previous work has shown that a prenatal HF diet impacts glucose tolerance, lipid profile, and cardiovascular health [31,33-35]. Such physiological characteristics have also been associated with DNA methylation [36-38], so it is possible that the perinatal diet acts through epigenetic mechanisms to affect metabolic outcomes.

The changes in DNA methylation but lack of body weight difference suggest that either perinatally programmed DNA methylation is slowly washed out by a new dietary challenge, or that DNA methylation programming is robust and foreshadows distinct future metabolic outcomes. Given previous findings, we hypothesize that our rats may have been sacrificed before weight differences could be observed. Because metabolic parameters such as resting metabolic rate, macronutrient oxidation, and body composition change during aging [39], it is possible that younger rats were able to compensate for perinatal perturbations. A similar principle might also explain the small number of differentially expressed genes. Younger animals might be better equipped to combat disturbances in the methylome. Conversely, it may be the case that DNA methylation established during the perinatal period is susceptible to change by post-weaning diet and thus yields no observable difference in the future metabolic outcome. Indeed, exposure to a post-weaning HF diet was shown to mitigate the epigenomic effects of the early-life diet [31]. Perinatal diet impacted 1,505 DMRs in male offspring given a post-weaning LF, but only 258 DMRs in offspring fed a post-weaning HF diet. We have also highlighted the important role of the post-weaning diet in establishing DNA methylation patterns [20]. While we previously found that a post-weaning HF diet increased body weight and impacted 3,966 DMRs, we show here that perinatal diet did not alter body weight and only affected 1419 DMRs. This suggests that post-weaning diet is a strong predictor of body weight and perhaps a more powerful determinant of DNA methylation than the perinatal diet. Future investigation should quantify the contributions of gestation, lactation, and post-weaning diet in determining DNA methylation levels in order to understand the dynamic nature of the methylome. Further work should also explore whether epigenetic alterations have the same impact on gene expression and weight gain in older individuals.

Altogether, we measured five differentially expressed genes. Two genes, Map3k5 and Igflr, contained intragenic DMRs. Previous studies suggested that the two genes respond to metabolic stressors. Map3k5 is activated by oxidative stress and inflammation [40], and Igf $1 \mathrm{r}$ participates in insulin signaling and fatty acid uptake [41,42]. Moreover, Map3k5 has been shown to be upregulated in the adipose tissue of obese individuals while Igflr is upregulated in lymphocytes of obese children $[43,44]$. Because a HF diet can induce oxidative stress and inflammation, it is not surprising that we observed lower expression of Map3k5 in LF-fed animals. Furthermore, the decrease in IgfIr expression in the LF group might be attributed to a reduced need for IGF1-mediated fatty acid uptake. Interestingly, expression of both genes was reduced under perinatal LF conditions, but while Igflr had a hypomethylated DMR, Map3k5 contained a hypermethylated DMR. This might have been due to the position of the DMRs relative to the TSS of each gene. In Igflr, the DMR was located in the first intron, where it could impact transcription in a canonical manner (i.e., increased DNA methylation resulting in decreased gene expression). The DMR associated with Map3k5 was located much further 
downstream of the TSS in intron 8. Several studies have suggested that gene body methylation might have non-traditional effects on transcription, which could account for the discrepancy we observed [45-47].

Amongst the genes associated with intergenic DMRs, Adh5, Enox1, and Pik3c3 were differentially expressed. Given their role in metabolic pathways, it is not surprising that these three genes were differentially expressed as a result of dietary treatments. The reactions catalyzed by Adh5 and Enox 1 both involve nicotinamine adenine dinucleotide (NAD). The balance between the oxidized and reduced form of the NAD cofactor is important for driving metabolic reactions. Pik3c3 plays a role in autophagy, which has been shown to be altered by different exposures to a HF diet [48-50]. We hypothesize that DNA methylation in more distant areas could be indicative of chromatin state, such that high methylation is correlated with closed chromatin [51]. This is reflected in the DNA methylation and gene expression patterns that we observed. Pik3c3 and Enox1 were expressed at lower levels in the LF group and the proximal DMRs were hypermethylated. Conversely, Adh5 was highly expressed in the LF group and the proximal DMR was hypomethylated.

This study provides insight into early life nutritional programming; however, limitations should be addressed in further experimentation. Here, we only explored dietary effects in male offspring. In previous studies, we have demonstrated sex-specific physiological and molecular changes after HF diet exposure [52-54]. We have also found particularly robust changes in hepatic gene expression and DNA methylation in male rats $[16,20,55,56]$. Although this study expands upon our prior findings in males, we cannot assume that these results would broadly apply to females. Further investigation is necessary to test whether diet-induced DNA methylation patterns are observed in both sexes. Another limitation of the current study is that epigenomic profiling was performed on whole liver tissue. While bulk tissue measurements have been previously used to uncover differences in hepatic gene expression and epigenetic profiles [57-59], future studies should consider isolating hepatocytes in order to better predict the functional role of differences in DNA methylation.

Our findings represent a novel contribution to the field of nutritional epigenetics. Whereas several other studies have taken gene-targeted approaches to study DNA methylation, we interrogated the entire epigenome to uncover novel differences in DNA methylation. This allowed us to better investigate intergenic DMRs. Previous analysis has focused on gene-associated DMRs located within $1,500 \mathrm{bp}$ upstream and downstream of a gene body. Indeed, certain technologies such as reduced representation bisulfite sequencing are designed to specifically identify DNA methylation differences in regions near gene promoters. Using these methods, the majority of identified DMRs have the advantage of being functionally interpretable. However, intergenic regions are often overlooked. Interestingly, we found intergenic DMRs to account for more than half of all differential methylation. Intergenic DNA methylation is thought to play an important in cellular function and disease. Intergenic DMRs can impact transcription via interaction with enhancer elements [60], and intergenic demethylation is observed in various cancers [61]. Currently, there are no bioinformatics approaches to identify specific functions for large numbers of intergenic DMRs. We hypothesized that proximal genes with significant chromatin contact were most likely to be affected by differential methylation. Although this hypothesis was supported by three differentially expressed genes, understanding the role of intergenic methylation should still be a priority in order to facilitate the development of new computational tools to annotate these regions.

\section{Conclusions}

Overall, we conclude that perinatal diet impacts hepatic DNA methylation, especially in metabolic and cancer-related pathways. On the other hand, early-life LF diet is not adequate to prevent postnatal weight gain induced by an HF diet. Although minimal, a prenatal LF diet produced changes in gene expression, including increased the expression of Map3k5, Igf1r, and Adh5, and decreased the expression of Enox1 and Pik3c3. Our findings suggest that diet-mediated epigenetic marks established during early life persist despite a HF diet challenge during the postnatal period. 
Author Contributions: Conceptualization, L.M., H.C., and Y.-X.P.; Formal analysis, L.M. and J.S.; Funding acquisition, H.C. and Y.-X.P.; Investigation, L.M. and J.S.; Methodology, L.M., J.S., and H.C.; Project administration, Y.-X.P.; Resources, H.C. and Y.-X.P.; Software, L.M. and H.C.; Supervision, Y.-X.P.; Visualization, L.M.; Writing-original draft, L.M.; Writing-review \& editing, L.M., J.S., H.C., and Y.-X.P.

Funding: This project was supported by UIUC Research Board grant \#12192, the USDA Cooperative State Research, Education and Extension Service, Hatch project numbers \# ILLU-971-344 and ILLU-698-391, and the Data Purchase Program from University Library.

Acknowledgments: We would like to thank Dan Zhou, Huan Wang, and Guanying Bianca Xu who contributed to the success of this study.

Conflicts of Interest: The authors declare no conflicts of interest.

\section{References}

1. Liu, Z.; Patil, I.Y.; Jiang, T.; Sancheti, H.; Walsh, J.P.; Stiles, B.L.; Yin, F.; Cadenas, E. High-fat diet induces hepatic insulin resistance and impairment of synaptic plasticity. PLoS ONE 2015, 10, e0128274. [CrossRef] [PubMed]

2. Sakamoto, E.; Seino, Y.; Fukami, A.; Mizutani, N.; Tsunekawa, S.; Ishikawa, K.; Ogata, H.; Uenishi, E.; Kamiya, H.; Hamada, Y.; et al. Ingestion of a moderate high-sucrose diet results in glucose intolerance with reduced liver glucokinase activity and impaired glucagon-like peptide-1 secretion. J. Diabetes Investig. 2012, 3, 432-440. [CrossRef] [PubMed]

3. Mauro, C.; Smith, J.; Cucchi, D.; Coe, D.; Fu, H.; Bonacina, F.; Baragetti, A.; Cermenati, G.; Caruso, D.; Mitro, N.; et al. Obesity-Induced Metabolic Stress Leads to Biased Effector Memory CD4(+) T Cell Differentiation via PI3K p110delta-Akt-Mediated Signals. Cell Metab. 2017, 25, 593-609. [CrossRef] [PubMed]

4. Sverdlov, A.L.; Elezaby, A.; Behring, J.B.; Bachschmid, M.M.; Luptak, I.; Tu, V.H.; Siwik, D.A.; Miller, E.J.; Liesa, M.; Shirihai, O.S.; et al. High fat, high sucrose diet causes cardiac mitochondrial dysfunction due in part to oxidative post-translational modification of mitochondrial complex II. J. Mol. Cell. Cardiol. 2015, 78, 165-173. [CrossRef] [PubMed]

5. Han, J.; Jiang, Y.; Liu, X.; Meng, Q.; Xi, Q.; Zhuang, Q.; Han, Y.; Gao, Y.; Ding, Q.; Wu, G. Dietary Fat Intake and Risk of Gastric Cancer: A Meta-Analysis of Observational Studies. PLoS ONE 2015, 10, e0138580. [CrossRef] [PubMed]

6. Ni, T.; He, Z.; Dai, Y.; Yao, J.; Guo, Q.; Wei, L. Oroxylin A suppresses the development and growth of colorectal cancer through reprogram of HIF1alpha-modulated fatty acid metabolism. Cell Death Dis. 2017, 8, e2865. [CrossRef] [PubMed]

7. de Almeida Faria, J.; Duque-Guimaraes, D.; Carpenter, A.A.; Loche, E.; Ozanne, S.E. A post-weaning obesogenic diet exacerbates the detrimental effects of maternal obesity on offspring insulin signaling in adipose tissue. Sci. Rep. 2017, 7, 44949. [CrossRef] [PubMed]

8. Kruse, M.; Seki, Y.; Vuguin, P.M.; Du, X.Q.; Fiallo, A.; Glenn, A.S.; Singer, S.; Breuhahn, K.; Katz, E.B.; Charron, M.J. High-fat intake during pregnancy and lactation exacerbates high-fat diet-induced complications in male offspring in mice. Endocrinology 2013, 154, 3565-3576. [CrossRef]

9. Loche, E.; Blackmore, H.L.; Carpenter, A.A.; Beeson, J.H.; Pinnock, A.; Ashmore, T.J.; Aiken, C.E.; de Almeida-Faria, J.; Schoonejans, J.M.; Giussani, D.A.; et al. Maternal diet-induced obesity programmes cardiac dysfunction in male mice independently of post-weaning diet. Cardiovasc. Res. 2018, 114, 1372-1384. [CrossRef]

10. Richmond, R.C.; Sharp, G.C.; Herbert, G.; Atkinson, C.; Taylor, C.; Bhattacharya, S.; Campbell, D.; Hall, M.; Kazmi, N.; Gaunt, T.; et al. The long-term impact of folic acid in pregnancy on offspring DNA methylation: Follow-up of the Aberdeen Folic Acid Supplementation Trial (AFAST). Int. J. Epidemiol. 2018. [CrossRef]

11. Pauwels, S.; Ghosh, M.; Duca, R.C.; Bekaert, B.; Freson, K.; Huybrechts, I.; Langie, S.A.S.; Koppen, G.; Devlieger, R.; Godderis, L. Maternal intake of methyl-group donors affects DNA methylation of metabolic genes in infants. Clin. Epigenetics 2017, 9, 16. [CrossRef] [PubMed]

12. Geraghty, A.A.; Lindsay, K.L.; Alberdi, G.; McAuliffe, F.M.; Gibney, E.R. Nutrition During Pregnancy Impacts Offspring's Epigenetic Status-Evidence from Human and Animal Studies. Nutr. Metab. Insights 2015, 8, 41-47. [CrossRef] [PubMed] 
13. Ge, Z.J.; Luo, S.M.; Lin, F.; Liang, Q.X.; Huang, L.; Wei, Y.C.; Hou, Y.; Han, Z.M.; Schatten, H.; Sun, Q.Y. DNA methylation in oocytes and liver of female mice and their offspring: Effects of high-fat-diet-induced obesity. Environ. Health Perspect. 2014, 122, 159-164. [CrossRef] [PubMed]

14. Ding, Y.; Li, J.; Liu, S.; Zhang, L.; Xiao, H.; Li, J.; Chen, H.; Petersen, R.B.; Huang, K.; Zheng, L. DNA hypomethylation of inflammation-associated genes in adipose tissue of female mice after multigenerational high fat diet feeding. Int. J. Obes. 2014, 38, 198-204. [CrossRef] [PubMed]

15. Dudley, K.J.; Sloboda, D.M.; Connor, K.L.; Beltrand, J.; Vickers, M.H. Offspring of mothers fed a high fat diet display hepatic cell cycle inhibition and associated changes in gene expression and DNA methylation. PLOS ONE 2011, 6, e21662. [CrossRef] [PubMed]

16. Zhang, Y.; Wang, H.; Zhou, D.; Moody, L.; Lezmi, S.; Chen, H.; Pan, Y.X. High-fat diet caused widespread epigenomic differences on hepatic methylome in rat. Physiol. Genom. 2015, 47, 514-523. [CrossRef] [PubMed]

17. Faa, G.; Sciot, R.; Farci, A.M.; Callea, F.; Ambu, R.; Congiu, T.; van Eyken, P.; Cappai, G.; Marras, A.; Costa, V.; et al. Iron concentration and distribution in the newborn liver. Liver 1994, 14, 193-199. [CrossRef] [PubMed]

18. Matsuzaki, S.; Onda, M.; Tajiri, T.; Kim, D.Y. Hepatic lobar differences in progression of chronic liver disease: Correlation of asialoglycoprotein scintigraphy and hepatic functional reserve. Hepatology 1997, 25, 828-832. [CrossRef] [PubMed]

19. Irwin, R.D.; Parker, J.S.; Lobenhofer, E.K.; Burka, L.T.; Blackshear, P.E.; Vallant, M.K.; Lebetkin, E.H.; Gerken, D.F.; Boorman, G.A. Transcriptional profiling of the left and median liver lobes of male f344/n rats following exposure to acetaminophen. Toxicol. Pathol. 2005, 33, 111-117.

20. Moody, L.; Chen, H.; Pan, Y.X. Postnatal diet remodels hepatic DNA methylation in metabolic pathways established by a maternal high-fat diet. Epigenomics 2017, 9, 1387-1402. [CrossRef]

21. Stevens, M.; Cheng, J.B.; Li, D.; Xie, M.; Hong, C.; Maire, C.L.; Ligon, K.L.; Hirst, M.; Marra, M.A.; Costello, J.F.; et al. Estimating absolute methylation levels at single-CpG resolution from methylation enrichment and restriction enzyme sequencing methods. Genome Res. 2013, 23, 1541-1553. [CrossRef] [PubMed]

22. Stevens, A.; Begum, G.; Cook, A.; Connor, K.; Rumball, C.; Oliver, M.; Challis, J.; Bloomfield, F.; White, A. Epigenetic changes in the hypothalamic proopiomelanocortin and glucocorticoid receptor genes in the ovine fetus after periconceptional undernutrition. Endocrinology 2010, 151, 3652-3664. [CrossRef] [PubMed]

23. Li, D.; Zhang, B.; Xing, X.; Wang, T. Combining MeDIP-seq and MRE-seq to investigate genome-wide CpG methylation. Methods 2015, 72, 29-40. [CrossRef] [PubMed]

24. Zhang, B.; Zhou, Y.; Lin, N.; Lowdon, R.F.; Hong, C.; Nagarajan, R.P.; Cheng, J.B.; Li, D.; Stevens, M.; Lee, H.J.; et al. Functional DNA methylation differences between tissues, cell types, and across individuals discovered using the M \& M algorithm. Genome Res. 2013, 23, 1522-1540. [PubMed]

25. Irizarry, R.A.; Ladd-Acosta, C.; Wen, B.; Wu, Z.; Montano, C.; Onyango, P.; Cui, H.; Gabo, K.; Rongione, M.; Webster, M.; et al. The human colon cancer methylome shows similar hypo-and hypermethylation at conserved tissue-specific CpG island shores. Nat. Genet. 2009, 41, 178-186. [CrossRef] [PubMed]

26. Dennis, G., Jr.; Sherman, B.T.; Hosack, D.A.; Yang, J.; Gao, W.; Lane, H.C.; Lempicki, R.A. DAVID: Database for Annotation, Visualization, and Integrated Discovery. Genome Biol. 2003, 4, R60. [CrossRef]

27. Leung, D.; Jung, I.; Rajagopal, N.; Schmitt, A.; Selvaraj, S.; Lee, A.Y.; Yen, C.A.; Lin, S.; Lin, Y.; Qiu, Y.; et al. Integrative analysis of haplotype-resolved epigenomes across human tissues. Nature 2015, 518, 350-354. [CrossRef]

28. Wang, Y.; Song, F.; Zhang, B.; Zhang, L.; Xu, J.; Kuang, D.; Li, D.; Choudhary, M.N.K.; Li, Y.; Hu, M.; et al. The 3D Genome Browser: A web-based browser for visualizing 3D genome organization and long-range chromatin interactions. Genome Biol. 2017, 19, 151. [CrossRef]

29. Wankhade, U.D.; Zhong, Y.; Kang, P.; Alfaro, M.; Chintapalli, S.V.; Thakali, K.M.; Shankar, K. Enhanced offspring predisposition to steatohepatitis with maternal high-fat diet is associated with epigenetic and microbiome alterations. PLoS ONE 2017, 12, e0175675. [CrossRef]

30. Turdi, S.; Ge, W.; Hu, N.; Bradley, K.M.; Wang, X.; Ren, J. Interaction between maternal and postnatal high fat diet leads to a greater risk of myocardial dysfunction in offspring via enhanced lipotoxicity, IRS-1 serine phosphorylation and mitochondrial defects. J. Mol. Cell. Cardiol. 2013, 55, 117-129. [CrossRef] 
31. Keleher, M.R.; Zaidi, R.; Shah, S.; Oakley, M.E.; Pavlatos, C.; El Idrissi, S.; Xing, X.; Li, D.; Wang, T.; Cheverud, J.M. Maternal high-fat diet associated with altered gene expression, DNA methylation, and obesity risk in mouse offspring. PLoS ONE 2018, 13, e0192606. [CrossRef] [PubMed]

32. Sheen, J.M.; Yu, H.R.; Tain, Y.L.; Tsai, W.L.; Tiao, M.M.; Lin, I.C.; Tsai, C.C.; Lin, Y.J.; Huang, L.T. Combined maternal and postnatal high-fat diet leads to metabolic syndrome and is effectively reversed by resveratrol: A multiple-organ study. Sci. Rep. 2018, 8, 5607. [CrossRef] [PubMed]

33. Zheng, J.; Xiao, X.; Zhang, Q.; Yu, M.; Xu, J.; Wang, Z. Maternal high-fat diet modulates hepatic glucose, lipid homeostasis and gene expression in the PPAR pathway in the early life of offspring. Int. J. Mol. Sci. 2014, 15, 14967-14983. [CrossRef] [PubMed]

34. Larsen, T.D.; Sabey, K.H.; Knutson, A.J.; Gandy, T.C.T.; Louwagie, E.J.; Lauterboeck, L.; Mdaki, K.S.; Baack, M.L. Diabetic Pregnancy and Maternal High-Fat Diet Impair Mitochondrial Dynamism in the Developing Fetal Rat Heart by Sex-Specific Mechanisms. Int. J. Mol. Sci. 2019, 20, 3090. [CrossRef] [PubMed]

35. Tamashiro, K.L.; Terrillion, C.E.; Hyun, J.; Koenig, J.I.; Moran, T.H. Prenatal stress or high-fat diet increases susceptibility to diet-induced obesity in rat offspring. Diabetes 2009, 58, 1116-1125. [CrossRef] [PubMed]

36. Kriebel, J.; Herder, C.; Rathmann, W.; Wahl, S.; Kunze, S.; Molnos, S.; Volkova, N.; Schramm, K.; Carstensen-Kirberg, M.; Waldenberger, M.; et al. Association between DNA Methylation in Whole Blood and Measures of Glucose Metabolism: KORA F4 Study. PLoS ONE 2016, 11, e0152314. [CrossRef] [PubMed]

37. Truong, V.; Huang, S.Y.; Dennis, J.; Lemire, M.; Zwingerman, N.; Aissi, D.; Kassam, I.; Perret, C.; Wells, P.; Morange, P.E.; et al. Blood triglyceride levels are associated with DNA methylation at the serine metabolism gene PHGDH. Sci. Rep. 2017, 7, 11207. [CrossRef] [PubMed]

38. Zhong, J.; Agha, G.; Baccarelli, A.A. The Role of DNA Methylation in Cardiovascular Risk and Disease Methodological Aspects, Study Design, and Data Analysis for Epidemiological Studies. Circ. Res. 2016, 118, 119-131. [CrossRef]

39. St-Onge, M.P.; Gallagher, D. Body composition changes with aging: The cause or the result of alterations in metabolic rate and macronutrient oxidation? Nutrition 2010, 26, 152-155. [CrossRef]

40. Matsukawa, J.; Matsuzawa, A.; Takeda, K.; Ichijo, H. The ASK1-MAP kinase cascades in mammalian stress response. J. Biochem. 2004, 136, 261-265. [CrossRef]

41. Steele-Perkins, G.; Turner, J.; Edman, J.C.; Hari, J.; Pierce, S.B.; Stover, C.; Rutter, W.J.; Roth, R.A. Expression and characterization of a functional human insulin-like growth factor I receptor. J. Biol. Chem. 1988, 263, 11486-11492. [PubMed]

42. Fernandez, A.M.; Kim, J.K.; Yakar, S.; Dupont, J.; Hernandez-Sanchez, C.; Castle, A.L.; Filmore, J.; Shulman, G.I.; Le Roith, D. Functional inactivation of the IGF-I and insulin receptors in skeletal muscle causes type 2 diabetes. Genes Dev. 2001, 15, 1926-1934. [CrossRef] [PubMed]

43. Ricco, R.C.; Ricco, R.G.; Queluz, M.C.; de Paula, M.T.S.; Atique, P.V.; Custodio, R.J.; Tourinho Filho, H.; Del Roio Liberatori, R., Jr.; Martinelli, C.E., Jr. IGF-1R mRNA expression is increased in obese children. Growth Horm. IGF Res. 2018, 39, 1-5. [CrossRef] [PubMed]

44. Bluher, M.; Bashan, N.; Shai, I.; Harman-Boehm, I.; Tarnovscki, T.; Avinaoch, E.; Stumvoll, M.; Dietrich, A.; Kloting, N.; Rudich, A. Activated Ask1-MKK4-p38MAPK/JNK stress signaling pathway in human omental fat tissue may link macrophage infiltration to whole-body Insulin sensitivity. J. Clin. Endocrinol. Metab. 2009, 94, 2507-2515. [CrossRef] [PubMed]

45. Ball, M.P.; Li, J.B.; Gao, Y.; Lee, J.H.; LeProust, E.M.; Park, I.H.; Xie, B.; Daley, G.Q.; Church, G.M. Targeted and genome-scale strategies reveal gene-body methylation signatures in human cells. Nat. Biotechnol. 2009, 27, 361-368. [CrossRef] [PubMed]

46. Jjingo, D.; Conley, A.B.; Yi, S.V.; Lunyak, V.V.; Jordan, I.K. On the presence and role of human gene-body DNA methylation. Oncotarget 2012, 3, 462-474. [CrossRef] [PubMed]

47. Yang, X.; Han, H.; De Carvalho, D.D.; Lay, F.D.; Jones, P.A.; Liang, G. Gene body methylation can alter gene expression and is a therapeutic target in cancer. Cancer Cell 2014, 26, 577-590. [CrossRef] [PubMed]

48. Che, Y.; Wang, Z.P.; Yuan, Y.; Zhang, N.; Jin, Y.G.; Wan, C.X.; Tang, Q.Z. Role of autophagy in a model of obesity: A long-term high fat diet induces cardiac dysfunction. Mol. Med. Rep. 2018, 18, 3251-3261. [CrossRef] [PubMed]

49. Papackova, Z.; Dankova, H.; Palenickova, E.; Kazdova, L.; Cahova, M. Effect of Short-and Long-Term High-Fat Feeding on Autophagy Flux and Lysosomal Activity in Rat Liver. Physiol. Res. 2012, 61, S67-S76. [PubMed] 
50. Yamamoto, T.; Takabatake, Y.; Takahashi, A.; Kimura, T.; Namba, T.; Matsuda, J.; Minami, S.; Kaimori, J.Y.; Matsui, I.; Matsusaka, T.; et al. High-Fat Diet-Induced Lysosomal Dysfunction and Impaired Autophagic Flux Contribute to Lipotoxicity in the Kidney. J. Am. Soc. Nephrol. 2017, 28, 1534-1551. [CrossRef] [PubMed]

51. Fortin, J.P.; Hansen, K.D. Reconstructing A/B compartments as revealed by Hi-C using long-range correlations in epigenetic data. Genome Biol. 2015, 16, 180. [CrossRef] [PubMed]

52. Strakovsky, R.S.; Wang, H.; Engeseth, N.J.; Flaws, J.A.; Helferich, W.G.; Pan, Y.X.; Lezmi, S. Developmental bisphenol A (BPA) exposure leads to sex-specific modification of hepatic gene expression and epigenome at birth that may exacerbate high-fat diet-induced hepatic steatosis. Toxicol. Appl. Pharmacol. 2015, 284, 101-112. [CrossRef] [PubMed]

53. Strakovsky, R.S.; Zhang, X.; Zhou, D.; Pan, Y.X. Gestational high fat diet programs hepatic phosphoenolpyruvate carboxykinase gene expression and histone modification in neonatal offspring rats. J. Physiol. 2011, 589, 2707-2717. [CrossRef] [PubMed]

54. Zhou, D.; Wang, H.; Cui, H.; Chen, H.; Pan, Y.X. Early-life exposure to high-fat diet may predispose rats to gender-specific hepatic fat accumulation by programming Pepck expression. J. Nutr. Biochem. 2015, 26, 433-440. [CrossRef] [PubMed]

55. Zhang, X.; Strakovsky, R.; Zhou, D.; Zhang, Y.; Pan, Y.X. A maternal high-fat diet represses the expression of antioxidant defense genes and induces the cellular senescence pathway in the liver of male offspring rats. J. Nutr. 2011, 141, 1254-1259. [CrossRef] [PubMed]

56. Moody, L.; Wang, H.; Jung, P.M.; Chen, H.; Pan, Y.X. Maternal and Post-weaning High-Fat Diets Produce Distinct DNA Methylation Patterns in Hepatic Metabolic Pathways within Specific Genomic Contexts. Int. J. Mol. Sci. 2019, 20, 3229. [CrossRef] [PubMed]

57. Yuan, X.; Tsujimoto, K.; Hashimoto, K.; Kawahori, K.; Hanzawa, N.; Hamaguchi, M.; Seki, T.; Nawa, M.; Ehara, T.; Kitamura, Y.; et al. Epigenetic modulation of Fgf21 in the perinatal mouse liver ameliorates diet-induced obesity in adulthood. Nat. Commun. 2018, 9, 636. [CrossRef] [PubMed]

58. Maegawa, S.; Lu, Y.; Tahara, T.; Lee, J.T.; Madzo, J.; Liang, S.; Jelinek, J.; Colman, R.J.; Issa, J.J. Caloric restriction delays age-related methylation drift. Nat. Commun. 2017, 8, 539. [CrossRef] [PubMed]

59. Guan, D.; Xiong, Y.; Borck, P.C.; Jang, C.; Doulias, P.T.; Papazyan, R.; Fang, B.; Jiang, C.; Zhang, Y.; Briggs, E.R.; et al. Diet-Induced Circadian Enhancer Remodeling Synchronizes Opposing Hepatic Lipid Metabolic Processes. Cell 2018, 174, 831-842. [CrossRef] [PubMed]

60. Thomas, R.M.; Sai, H.; Wells, A.D. Conserved intergenic elements and DNA methylation cooperate to regulate transcription at the il17 locus. J. Biol. Chem. 2012, 287, 25049-25059. [CrossRef] [PubMed]

61. Caplakova, V.; Babusikova, E.; Blahovcova, E.; Balharek, T.; Zelieskova, M.; Hatok, J. DNA Methylation Machinery in the Endometrium and Endometrial Cancer. Anticancer Res. 2016, 36, 4407-4420. [CrossRef] [PubMed]

(C) 2019 by the authors. Licensee MDPI, Basel, Switzerland. This article is an open access article distributed under the terms and conditions of the Creative Commons Attribution (CC BY) license (http://creativecommons.org/licenses/by/4.0/). 